\title{
Pregnancy recognition signals in mammals: the roles of interferons and estrogens
}

\author{
Fuller W. Bazer ${ }^{1,3}$, Guoyao Wu ${ }^{1}$, Greg A. Johnson ${ }^{2}$ \\ ${ }^{1}$ Departments of Animal Science and ${ }^{2}$ Veterinary Integrative Biosciences, Texas A\&M University, College Station,
} TX, USA.

\begin{abstract}
Reproduction is a highly complex biological process requiring a dialogue between the developing conceptus (embryo-fetus and associated placental membranes) and maternal uterus which must be established during the peri-implantation period for pregnancy recognition signaling and regulation of gene expression by uterine epithelial and stromal cells. The uterus provide a microenvironment in which molecules secreted by uterine epithelia or transported into the uterine lumen represent histotroph or the secretome required for growth and development of the conceptus and receptivity of the uterus to implantation by the conceptus. Pregnancy recognition signaling as related to sustaining the functional lifespan of the corpora lutea (CL) which produce progesterone; the hormone of pregnancy essential for uterine functions that support implantation and placentation required for successful outcomes of pregnancy. It is within the periimplantation period that most embryonic deaths occur in mammals due to deficiencies attributed to uterine functions or failure of the conceptus to develop appropriately, signal pregnancy recognition and/or undergo implantation and placentation. The endocrine status of the pregnant female and her nutritional status are critical for successful establishment and maintenance of pregnancy. The challenge is to understand the complexity of key mechanisms that are characteristic of successful reproduction and to use that knowledge to enhance fertility and reproductive health of animals including nonhuman primates. It is important to translate knowledge gained from studies of animals to address issues of fertility and reproductive health in humans.
\end{abstract}

Keywords: Pregnancy recognition, interferon tau, estrogen, prolactin, mammals

\section{Introduction}

The endocrinology of recurring estrous/menstrual cycles and pregnancy in primates, ruminants, swine, horses, cats, dogs and rodents includes hormonal signaling for maternal recognition of pregnancy and the endocrinology of pregnancy. The estrous cycle of subprimate species is uterinedependent, because the uterus produces prostaglandin F2 $\alpha$ (PGF), the luteolytic hormone responsible for functional and structural regression of the ovarian corpus luteum (CL) in the absence of an appropriate maternal recognition of pregnancy signal from the conceptus (embryo and its extra-embryonic membranes). In primates, however, the menstrual cycle is uterine-independent as luteolytic PGF is produced within the ovaries. During the peri-implantation period of pregnancy, maternal recognition of pregnancy signals from the conceptus to the maternal system are either antiluteolytic or luteotrophic. Antiluteolytic signals prevent uterine release of luteolytic PGF while luteotrophic signals act directly on the CL to prevent luteolysis. The functional lifespan of the $\mathrm{CL}$ is controlled by the timing of release of PGF from the uterus and/or ovary, while maternal recognition of pregnancy signals from the conceptus may act in either a paracrine or endocrine manner to prevent uterine and/or ovarian release of luteolytic PGF (Fig. 1). Following successful signaling for maternal recognition and establishment of pregnancy, progesterone (P4) from the $\mathrm{CL}$ and numerous hormones from the placenta are required for maintenance of pregnancy and birth of viable offspring.

\section{Corpus luteum (CL) formation and regression}

Mammals may be spontaneous ovulators (e.g. ruminants, pigs, horses, and primates), induced ovulators (e.g., rabbit and cat) or spontaneous ovulators with induced CL (mice and rats). Except for primates, the estrous cycle is dependent on the uterine production of luteolytic PGF for functional (cessation of P4 production) and structural (luteal cell death) regression of the CL (Stouffer, 1988). In ruminants, luteolytic pulses of PGF are released by uterine luminal (LE) and superficial glandular epithelia (sGE) that are expressing receptors for estrogens (ESR1) and oxytocin (OXTR), as well as prostaglandin synthase 2 (PTGS2), the rate limiting enzyme in synthesis of prostaglandins. The uterine luteolytic mechanism requires sequential effects of P4, estradiol (E2) and oxytocin (OXT) acting through their respective receptors on uterine $\mathrm{LE} / \mathrm{sGE}$ to stimulate accumulation of phospholipids, expression of OXTR and release of oxytocin (OXT)-induced luteolytic pulses of PGF (Spencer et al., 2004). At onset of estrus (day 0), estrogens from mature Graafian follicles increase expression of ESR1, progesterone receptor (PGR) and OXTR, respectively. During diestrus, P4 from the CL: 1) stimulates accumulation of phospholipids in LE/sGE that liberates arachidonic acid for synthesis and secretion of PGF; 2) acts via PGR to "block" expression of ESR1 and OXTR in uterine LE/sGE for 10 to 12 days; and 3) down-regulates PGR expression by LE/sGE between days 11 and 13 to release the "P4 block" to expression of ESR1 and then OXTR necessary for OXT-induced release of luteolytic 
pulses of PGF required for regression of the CL. The promoter region of the ovine OXTR gene contains $\mathrm{Sp} 1$ response elements that mediate responsiveness to liganded ESR1 that increases transcription of OXTR in uterine LE/sGE. Continuous exposure of the uterus to P4 for 10 to 12 days down-regulates PGR in endometrial LE/sGE to allow a rapid increase in ESR1 in those cells beginning on day 13 and OXTR increase from days 14 to 17 in cyclic ewes. The mechanism responsible for P4-induced down-regulation of PGR is not known. In ewes, pulsatile release of OXT from the posterior pituitary gland and $\mathrm{CL}$ induces coordinate release of luteolytic pulses of PGF from uterine LE/sGE on days 15 and 16 to induce CL regression.
Pregnancy recognition signals for maintenance of $C L$

Pregnancy is established and maintained in subprimate mammals in response to signaling from the conceptus and/or anterior pituitary to the uterus and/or $\mathrm{CL}$ to exert antiluteolytic effects that prevent uterine release of PGF or act as a luteotrophic signal to directly stimulate development and function of the CL. Although the luteolytic mechanism in primates remains unclear, chorionic gonadotrophin beta subunit (CGB) is the luteotrophin required to extend lifespan of the $\mathrm{CL}$ and it is produced by primate blastocysts during the peri-implantation period to signal maternal recognition of pregnancy.

\section{Pregnancy Recognition Signaling}

\section{Corpus Luteum (CL) \\ Maintenance \\ Progesterone: The \\ Hormone of Pregnancy! \\ Antiluteolytic \\ IFNT - Ruminants \\ Estradiol/PRL- Pigs \\ Luteotrophic \\ CGB - Primates \\ PRL - Rodents \\ Lactogenic \\ Hormones}

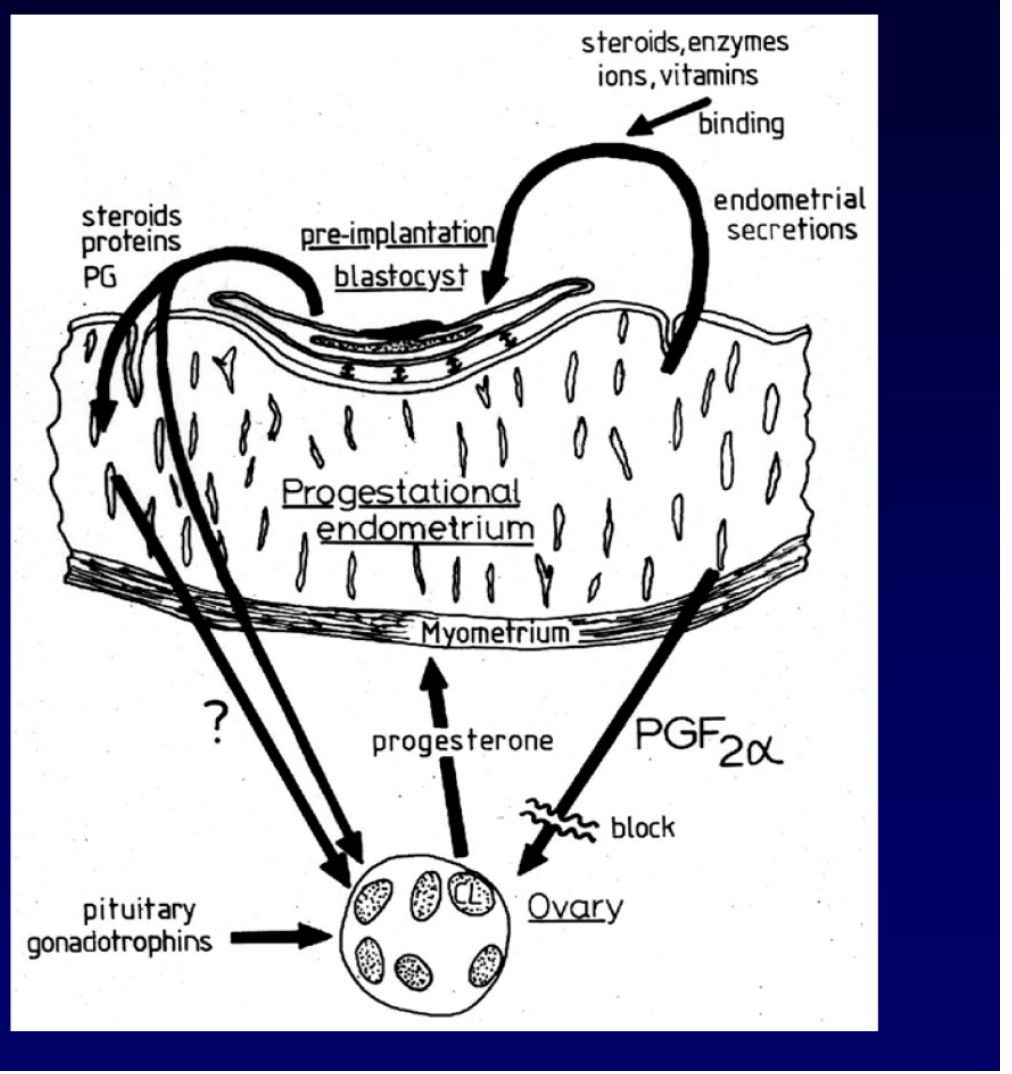

Figure 1. Interferon tau (IFNT) and estradiol in concert with prolactin (PRL) are antiluteolytic pregnancy recognition signals from trophectoderm cells of ruminant and porcine species whereas chorionic beta (CGB) and lactogenic hormones such as PRL and placental lactogens act directly on the corpus luteum as luteotrophic signals. In each case, one or more functional corpora lutea are maintained to produce progesterone which is required for establishment and maintenance of pregnancy (see Bazer et al., 2009b).

Luteinizing hormone (LH), chorionic gonadotophin beta chain (CGB) and LH/CG Receptor (LHCGR; see Rao, 2001; Ziecik et al., 2007)

LH, a dimeric glycoprotein, shares a common alpha subunit with follicle stimulating hormone (FSH), thyroid stimulating hormone (TSH) and CGB. However, although the beta subunit of LH (LHB) and CG (CGB) both bind to and transactivate the $\mathrm{LH} / \mathrm{CG}$ receptor (LHCGR), they are unique and confer different biological activities and immunological identities. Binding of LH or CGB to LHCGR activates a G protein bound to the cytoplasmic domain of the LHCGR which detaches from LHCGR to activate the cAMP system and cAMP-dependent protein kinases (protein kinase A). The PKAs are tetramers with two regulatory and 
two catalytic subunits. Upon binding cAMP by the regulatory units, the catalytic units are released to initiate phosphorylation of proteins that then activate genes that effect biological responses. LH acts on mature Graffian follicles to induce ovulation and luteinization of theca and granulosa cells that form the $\mathrm{CL}$ and produce P4. Basal output of $\mathrm{LH}$ from the anterior pituitary is permissive for maintenance of CL function in most species. However, CGB from trophectoderm/chorion is the maternal recognition of pregnancy signal in primates. In addition, LH and CGB bind LHCGR expressed in the myometrium, endometrium, oviduct, broad ligament, uterine blood vessels, cervix, mammary gland, placenta and umbilical cord of females, the epididymis and prostate glands of males, and the brain, adrenal glands, skin and lymphocytes of both sexes. Inactivation of LHCGR in mice by gene targeting revealed that: 1) mice were viable and had normal differentiation of the gonads and reproductive tract; 2) there is a lack of redundancy for LH signaling for ovarian follicular growth beyond the antral stage and ovum maturation; 3) initiation of pregnancy requires LH signaling; and 4) LH signaling is required to maintain expression of ESR1 and steroidogenic acute regulatory protein in ovaries and testes. In pigs, LH contributes to quiescence of myometrium and, directly or indirectly, production of prostanoids that stimulate uterine blood flow.

\section{Progesterone (P4) and progesterone receptors (PGR)}

As noted previously, a maternal recognition of pregnancy signal is required in most mammals for maintenance of a functional $\mathrm{CL}$ for production of $\mathrm{P} 4$, the hormone of pregnancy. Progesterone is required for a uterine environment supportive of implantation, placentation, and development of viable offspring, as well as mammogenesis and lactogenesis for nutritional support of the newborn during the neonatal and postnatal periods (see Bazer et al., 2009b, c). Uterine receptivity to implantation of blastocysts is dependent on $\mathrm{P} 4$ which is permissive to actions of interferons (IFN) such as interferon tau (IFNT) in ruminants, CGB and lactogenic hormones such as prolactin (PRL) and chorionic somatomammotropin hormone 1 (placental lactogen; CSH1). An interesting paradox is that downregulation of PGR and ESR1 by uterine epithelia is a prerequisite for uterine receptivity to implantation, expression of genes for secretory proteins, and selective transport of molecules into the uterine lumen that support conceptus development. Down-regulation of PGR correlates with a loss of expression of proteins on uterine $\mathrm{LE} / \mathrm{sGE}$, such as cell surface associated mucin 1 (MUC1) that would otherwise interfere with implantation. However, P4 does not down-regulate PGR in uterine stromal cells. Thus, P4 potentially acts via PGR-positive uterine stromal cells to induce expression of progestamedins that include fibroblast growth factor7 (FGF7) and -10 (FGF10) and hepatocyte growth factor (HGF) that exert paracrine effects on uterine epithelia. Further, conceptus trophectoderm and uterine epithelia express receptors for FGF7 and FGF10 (fibroblast growth factor receptor 2 splice variant or FGFR2IIIb) and HGF (met proto-oncogene or MET). In sheep and perhaps other ruminants, a select set of genes expressed by uterine LE/sGE are P4-induced and IFNT stimulated. The uterine LE/sGE do not express PGR or signal transducers and activators of transcription (STAT1). Therefore, a fundamental unanswered question is whether actions of progestamedins and IFNs on uterine LE/sGE involves non-classical cell signaling pathways independent of PGR and STAT1, such as mitogen activated protein kinases (MAPK) and phosphoinositide-3 kinase (PI3K; Plantanias, 2005). Indeed, IFNT activates cell signaling pathways to differentially affect gene expression in uterine LE/sGE compared to GE and stromal cells in sheep. Interferon tau induces expression of interferon regulatory factor 2 (IRF2) in uterine LE/sGE. IRF2 is a potent transcriptional repressor limited to uterine LE/sGE and it inhibits expression of most classical IFN-stimulated genes (ISGs) and ESR1, but IRF2 is not expressed in GE or stromal cells which allows for induction of expression of ISGs by IFNT in those cells.

The role of membrane receptors for progesterone (mPRs) in uterine epithelia and stromal cells for rapid nongenomic responses to $\mathrm{P} 4$ is not known. Known mPRs include progesterone receptor membrane components 1 and 2 (PRMC1 and PMRC2), membrane progesterone receptors $\mathrm{a}, \mathrm{b}$ and $\mathrm{c}$ (MPRA, MPRB and MPRG), and hypothetical RNA-binding protein (RDA288; see Gellerson et al., 2008; Nillson et al., 2006; Thomas, 2008). The biological effects of P4 mediated via mPR include induction of oöcyte maturation and hypermotility of sperm in fish, some uterine functions, and $\mathrm{GnRH}$ secretion in rodents. PGMRC1 and PGMRC2 have predicted motifs for tyrosine kinase, kinase binding, $\mathrm{SH} 2$ and $\mathrm{SH} 3$ based on their amino acid sequences. PGMRC1 mediates antiapoptotic effects of $\mathrm{P} 4$ in rat granulosa cells and perhaps P4-induction of the acrosome reaction in mammalian sperm. The mPR subtypes detected in fish and mammals have a subcellular localization for progestin binding and $G$ protein coupling for cell signaling. These subtypes are expressed in different tissues and have different patterns of expression which suggests different physiological functions in the female reproductive tract. For example, MPRA mRNA is expressed in ovary, testis, amnion, chorion and uterine endometrium and myometrium, kidney, adrenal gland, mammary gland, hypothalamus, pituitary, ovary, brain, testes and lymphocytes of mammals. PGMRC1 and PGMRC2 are also expressed in tissues of the female reproductive tract, particularly the ovary. The physiological relevance of membrane progesterone receptors in mediating actions of $\mathrm{P} 4$ in reproductive organs is largely unknown.

\section{Pregnancy recognition signaling}

\section{Ruminants}

Estrous cycle and luteolysis

Ruminants, e.g., cattle, sheep and goats, are 
spontaneously ovulating, polyestrous mammals with recurring estrous cycles of 21,17 and 20 days, respectively (see Spencer et al., 2004, 2007). Domestic cattle are not seasonal breeders, but sheep (Ovis aries) and goats (Capra hircus) are short-day breeders with regular estrous cycles from late summer through midwinter. Sheep have been studied in greatest detail with respect to endocrine regulation of the estrous cycle and pregnancy; however, the basic mechanisms for luteolysis and maternal recognition of pregnancy are very similar for ewes, cows and nannies.

In ewes, estrus, designated as day 0 , is the day of onset of sexual receptivity for mating and the beginning of the estrous cycle. Estrus lasts about $30 \mathrm{~h}$ and spontaneous ovulation occurs about $30 \mathrm{~h}$ after onset of estrus in response to an estrogen-induced ovulatory surge of LH and FSH from the anterior pituitary at the onset of estrus. Metestrus, days 1 to 4 of the estrous cycle, is characterized by luteinization of theca and granulosa cells of the ovarian follicle under the influence of $\mathrm{LH}$ to form the $\mathrm{CL}$ which secretes $\mathrm{P} 4$. Diestrus, days 4 to 14 of the estrous cycle, is when the CL reaches its maximum size and secretion of $\mathrm{P} 4$. Near the end of diestrus PGR in uterine epithelia are downregulated by $\mathrm{P} 4$ to allow increases in ESR1 and then OXTR necessary for OXT-induced secretion of luteolytic PGF and regression of the CL. The onset of proestrus begins when the CL is fully regressed and ovarian follicles begin producing significant amounts of estradiol (E2). A dominant follicle(s) is selected for ovulation and onset of estrus marks the beginning of the next estrous cycle. The estrous cycle of ruminants is dependent on the uterine endometrium for production of luteolytic PGF and regression of the $\mathrm{CL}$ as described previously. If ewes are hysterectomized during the active life of the CL, the uterine source of PGF is removed; therefore, CL life span is prolonged to about five months, i.e., similar to the duration of normal pregnancy.

\section{Pregnancy}

The antiluteolytic signal for maternal recognition of pregnancy in ruminants is interferon tau (IFNT) produced by the mononuclear trophectoderm cells of the conceptus (Spencer et al., 2007; Bazer et al., 2008). The effect of IFNT in abrogating the uterine luteolytic mechanism for maternal recognition of pregnancy signaling is very similar for ewes, cows and nanny goats. IFNT, a Type I IFN, has potent antiviral, antiproliferative and immunomodulatory activities, as well as its unique role as the maternal recognition of pregnancy signal in ruminants. IFNT is produced in massive amounts as conceptus trophectoderm undergoes a morphological transition from spherical to tubular and filamentous forms during the peri-implantation period of pregnancy. Ovine IFNT is not glycosylated, whereas 100 percent of bovine IFNT is glycosylated and about 50 percent of caprine IFNT is glycosylated. Ovine IFNT delivered into the uterine lumen of cows and nanny goats extends the inter-estrous interval significantly and it suppresses OXT-induced PGF production by bovine and caprine uteri (Fig. 2).

All Type I IFNs bind a common receptor composed of two subunits, IFNAR1 (interferonalpha/beta receptor alpha chain) and IFNAR2 (interferon-alpha/beta receptor beta chain), to induce cell signaling via the classical Janus activated kinases (JAKs) and STAT1 pathway. However, several nonclassical ISGs are P4-induced and IFN-stimulated in ovine uterine LE/sGE which lack both PGR and STAT1. Therefore, the actions of P4 and IFNT may by through combined effects of a progestamedin(s), e.g., FGF10 in sheep, and a non-classical cell signaling pathway(s) for IFNT, such as MAPK and PI3K pathways to affect gene expression and uterine receptivity to implantation (Plantanias, 2005; Bazer et al., 2009b). Restriction of expression of classical ISGs by ovine uterine LE/sGE is due, at least in part, to expression of interferon regulatory factor 2 (IRF2), a potent transcriptional repressor, in those cells, but IRF2 is not expressed in uterine GE and stromal cells.

Secretion of ovine IFNT begins on about day 10 and increases as conceptuses undergo morphological changes from spherical (312 $\mathrm{ng} / \mathrm{ml}$ uterine flush) to tubular $(1,380 \mathrm{ng})$ and filamentous $(4,455 \mathrm{ng})$ forms between days 12 and 13 of pregnancy. Successful transfer of conceptuses to cyclic ewes can occur as late as day 12 , i.e., 48 to $72 \mathrm{~h}$ prior to the luteolytic period. Thus, IFNT acts to abrogate the uterine luteolytic mechanism and prevent pulsatile release of PGF. Intrauterine infusion of IFNT from day 11 to day 15 of the estrous cycle prevents luteolysis and extends CL lifespan. The antiluteolytic effects of IFNT are primarily on uterine LE/sGE in ewes. IFNT silences transcription of ESR1 and, therefore, ESR1-induced expression of the OXTR gene in uterine LE/sGE to prevent development of the endometrial luteolytic mechanism that requires pulsatile release of PGF. However, basal production of PGF is actually higher in pregnant than cyclic ewes due to continued expression of PTGS2 in the uterine LE/sGE. Further, silencing ESR1 expression by IFNT prevents E2 and ESR1 from inducing PGR in endometrial epithelia. The absence of PGR in uterine epithelia is required for expression of a unique set of $\mathrm{P} 4$-induced and IFNT-stimulated genes in ovine uterine LE/sGE during early pregnancy. For most, if not all, actions of IFNT on the uterus, P4 is the permissive hormone. That is, uterine receptivity to implantation is P4-dependent, but is preceded by loss of expression of PGR and ESR1 by uterine epithelia, and the loss of PGR is a prerequisite for expression of several ISGs in ewes. Thus, P4 likely acts on PGR-positive stromal cells to increase expression of a progestamedin(s) in ewes, likely FGF10, that exerts paracrine effects on uterine epithelia and conceptus trophectoderm that express its receptor FGFR2IIIb. In sheep, classical ISGs (e.g., interferon stimulated gene 15, mouse myxovirus resistance 1 and 2', 5' oligoadenylate synthase) are induced by IFNT only in uterine GE, stroma and immune cells that do not express IRF2. 


\section{INTERFERON TAU AND UTERINE FUNCTIONS}

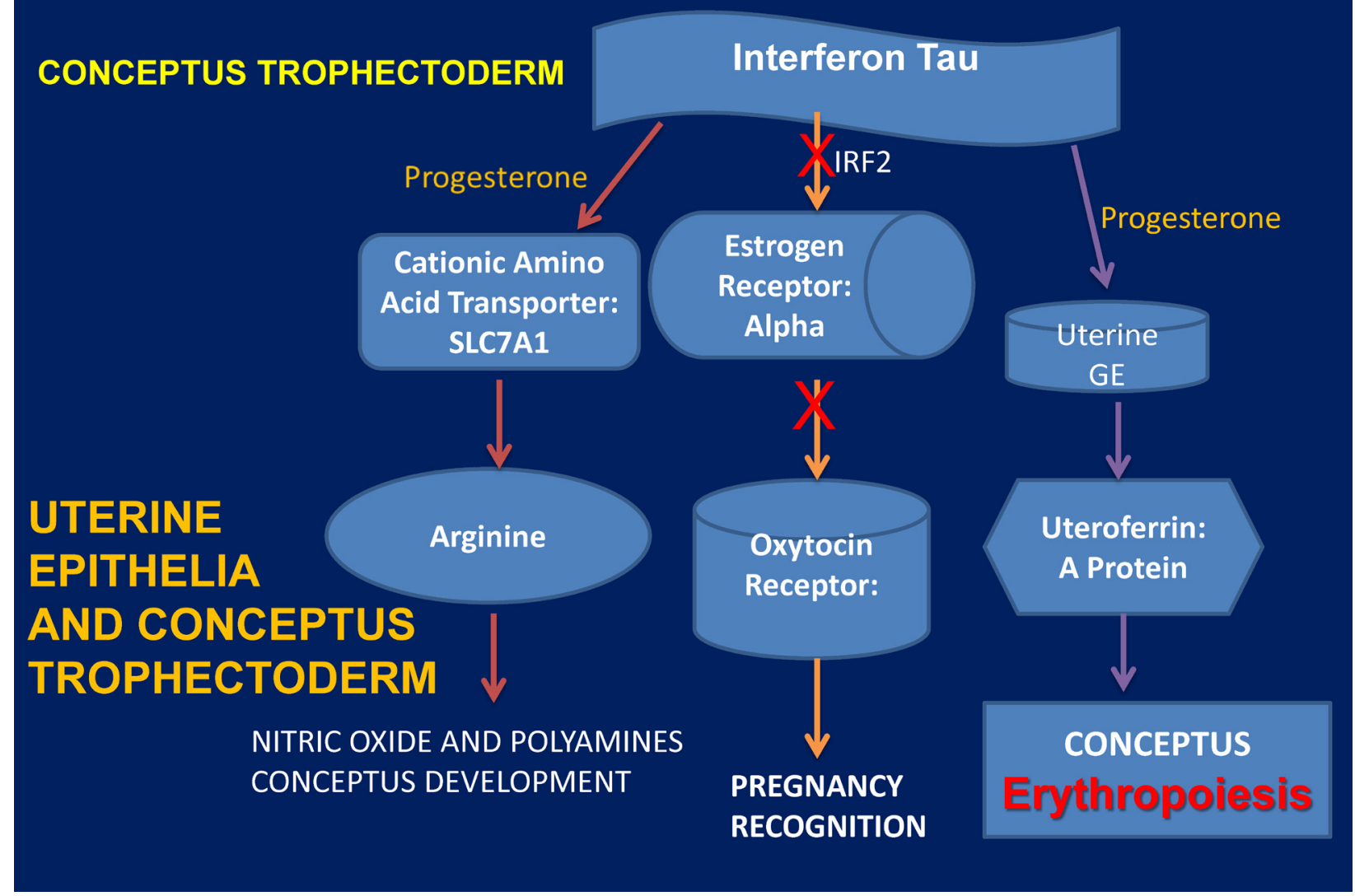

Figure 2. Interferon tau is not only the pregnancy recognition signal that induces expression of interferon regulatory factor 2 (IRF2) which silences expression of receptors for estrogen (estrogen receptor alpha) and oxytocin (oxytocin receptor) to prevent uterine release of luteolytic pulses of prostaglandin F2 $\alpha$. In concert with progesterone, interferon tau also increases expression of nutrient transporters such as SLC7A1 for transport of arginine into the trophectoderm cells. Arginine is then metabolized to nitric oxide and polyamines that are required for growth and development of the conceptus. Interferon tau, in concert with progesterone, also increases expression of uteroferrin which not only transport iron to the conceptus, but also stimulates erythropoiesis (see Bazer et al., 2009b, 2015).

\section{Cows}

Bovine IFNT is secreted between days 12 and 38 of pregnancy and activates mechanisms that prevent uterine secretion of luteolytic pulses of PGF (see Thatcher et al., 2001). Similar to ewes, neither exogenous E2 nor OXT stimulate uterine release of PGF in cows receiving intra-uterine ovine IFNT. Therefore, it appears that ESR1 and OXTR mRNA are either less abundant or not responsive to E2 and OXT in endometria of pregnant compared to cyclic cows, and in cows that received intra-uterine injections of ovine IFNT.

\section{Goats}

Caprine IFNT is secreted between days 16 and 21 of gestation to prevent pulsatile release of luteolytic PGF (Newton et al., 1996). Intra-uterine injections of ovine IFNT in nanny goats extends CL lifespan.

\section{Pregnancy in ruminants}

In sheep, establishment and maintenance of pregnancy requires integration of endocrine and paracrine signals from the ovary, conceptus, and uterus (Spencer and Bazer, 2004). Superficial implantation and placentation occur between days 15 and 60 of pregnancy as the uterus grows and remodels to accommodate development and growth of the conceptus in the last trimester of pregnancy. In addition, caruncles and cotyledons develop and interdigitate to form placentomes which increase in vascularity and the intercaruncular endometrial glands grow substantially during pregnancy to secrete increasing amounts of histotroph that is transported across the areolae of the chorioallantois into the fetal-placental circulation. During gestation, endometrial gland hyperplasia occurs between days 15 and 50 and is followed by hypertrophy for maximal production of histotroph after day 60 . During this period, the pregnant ovine uterus is exposed sequentially to E2, P4, IFNT, placental lactogern (CSH1), and placental growth hormone (GH1) that regulate endometrial gland morphogenesis and differentiated functions of uterine GE. The binucleate cells of the chorion secrete CSH1 from day 15 or 16 of 
pregnancy which is coordinate with initiation of expression of uterine milk proteins (UTMP; serpin family of serine protease inhibitors) and secreted phosphoprotein 1(SPP1 or osteopontin; an extracellular matrix protein) that are excellent markers of differentiated function and secretory capacity of uterine GE. CSH1 is detectable in maternal blood by day 50 and peaks between days 120 and 130 of pregnancy. CSH1 can bind either homodimers of the prolactin receptor (PRLR) or heterodimers of PRLR and GH1 receptors (GHR) to transduce cell signaling. In the ovine uterus, PRLR are specifically expressed in GE and CSH1 stimulates hyperplasia and hypertrophy of uterine GE and their production of UTMP, SPP1 and other components of histotroph that support growth and development of the conceptus. Sequential exposure of the pregnant ovine endometrium to E2, P4, IFNT, CSH1 and $\mathrm{GH} 1$ constitutes a "servomechanism" that activates and maintains endometrial remodeling, secretory function, and uterine growth during gestation. The chronic effect of P4 is to inhibit expression of PGR by uterine LE/sGE and GE to allow expression of proteins by uterine $\mathrm{GE}$, while $\mathrm{CSH} 1$ and $\mathrm{GH}$ increase the number of endometrial glands and levels of expression of genes encoding for proteins such as UTMP and SPP1. The net effect in ewes is a developmentally programmed sequence of events, mediated by specific paracrine-acting factors at the conceptus-endometrial interface that stimulate both inter-caruncular endometrial remodeling and differentiated function of uterine GE for increased production of histotroph to support fetal-placental growth.

\section{Pregnancy in pigs}

The estrous cycle and luteolysis

Pigs are a spontaneously-ovulating, polyestrous, litter-bearing species that reach puberty between 4 and 9 months of age depending on breed, nutritional status and housing conditions (see Anderson, 1993). For gilts (nonparous) and sows (parous) lengths of estrous cycles average 21 days (range 18-24 days). Estrus lasts 40 to $60 \mathrm{~h}$ with gilts exhibiting shorter periods of estrus than sows. Estrus, a behavioral response to estrogens from ovarian follicles, also stimulates a protracted ovulatory surge of LH resulting in ovulation about 44 hours after onset of estrus. The number of follicles ovulated ranges from 8 to 10 at the pubertal estrus to more than 20 for sows. Levels of circulating P4 increase from metestrus (days 3 to 5) to 20 to $40 \mathrm{ng} / \mathrm{ml}$ at mid-diestrus (days 6 to 14) and, in the absence of pregnancy, uterine release of luteolyic PGF occurs between day 16 and 18 to regress the CL and allow a new wave of follicles to develop and secrete estrogens during proestrus (days 18 to onset of estrus). Circulating concentrations of estrogens reach peak values about two days prior to onset of estrus. Concentrations of prolactin (PRL) in serum are greatest during proestrus and estrus while levels of relaxin (RLX) from the CL are low during estrus and highest during diestrus.

Endocrine requirements for luteolysis in pigs are not well defined; however, luteolysis occurs during late diestrus and proestrus following stimulation of the uterine endometrium by $\mathrm{P} 4$ for 10 to 12 days to allow accumulation of phospholipids and necessary enzymes for production of luteolytic pulses of PGF (see Spencer et al., 2004). Hysterectomy extends CL function to about 120 days due to removal of the uterine source of PGF. Further, the CL of pigs are refractory to luteolytic effects of PGF until days 12-13 of the estrous cycle due to low numbers of PGF receptors (PTGFR) on luteal cells. In ruminants, OXT from the $\mathrm{CL}$ and posterior pituitary act via uterine OXTR to elicit pulsatile release of PGF; however, CL of pigs contain very low amounts of OXT and vasopressin. Thus, the role(s) of those neuropeptides in luteolysis in pigs is not known. In fact, the uterine endometrium is a source of OXT in pigs, but its role is not known. Administration of exogenous OXT does decrease the inter-estrous interval in gilts when administered between days 10 and 16 post-estrus, but not when administered to ovary-intact hysterectomized gilts, suggesting that the effect of OXT is uterinedependent. The endometrium of pigs contains receptors for OXT and lysine vasopressin, but only responds to OXT with increased secretion of PGF whereas both peptides stimulate inositol phosphate turnover indicative of stimulation of the protein kinase $\mathrm{C}$ and calciumcalmodulin kinase cell signaling pathways. OXT stimulates phospholipase C activity and phosphatidylinositol hydrolysis increases intracellular concentrations of calcium and diacylglycerol which activate protein kinase $\mathrm{C}$ and calcium-calmodulin kinase to activate phospholipase $\mathrm{A} 2$, release of arachidonic acid and increased production of PGF in pigs. Although concentrations of OXT increase in the peripheral circulation during luteolysis, OXT-induced increases in circulating concentrations of PGFM are lower in pregnant than cyclic gilts or gilts induced into pseudopregnancy by daily injections of exogenous E2 between days 11 and 15 post-estrus. Prostaglandins, however, are critical for establishment of pregnancy in pigs as inhibition of prostaglandin synthesis results in pregnancy failure and basal concentrations of PGFM in the circulation are elevated in pregnant gilts beginning on day 12 .

\section{Pregnancy}

After hatching from the zona pellucida, pig blastocysts expand and undergo morphological transition to spherical (10 to $15 \mathrm{~mm}$ diameter), tubular (15 by $50 \mathrm{~mm}$ ) and filamentous (1 by $100-200 \mathrm{~mm}$ ) forms between days 10 and 12 of pregnancy and achieve a length of 800 to $1000 \mathrm{~mm}$ between days 12 and 15 of pregnancy (see Bazer and Johnson, 2014). During rapid elongation of the trophectoderm, pig conceptuses produce estrogens, as well as interferons gamma (IFNG) and delta (IFND). The pregnancy recognition signal is E2 produced by the conceptus from days 11 and 12 to day 15 of pregnancy that directs secretion of PGF away from the uterine vasculature and into the uterine lumen (exocrine secretion) where it is sequestered and metabolized to prevent luteolysis. In 
nonpregnant gilts, PGF is released from the uterine endometrium into the venous drainage (endocrine secretion) to be transported to the CL via the vascular system to induce luteolysis.

The conceptus estrogens also modulate uterine gene expression responsible for endometrial remodeling for implantation between days 13 and 25 of gestation. Both SPP1 and FGF7 are induced by estrogen in uterine LE to affect trophectoderm growth and development, as well as adhesion to LE for signal transduction and cell migration during the peri-implantation period (White et al., 2005; Ka et al., 2007). The trophectoderm also secretes interleukin 1 beta (IL1B) and E2 modulates uterine responses to IL1B (Geisert and Yelich, 1997). On day 15 of pregnancy, IFNG and IFND colocalize to perinuclear membranes typically occupied by endoplasmic reticulum and golgi apparatus, as well as cytoplasmic vesicles within clusters of trophectoderm cells along the endometrial LE. Their expression is accompanied by the appearance of zona occludens one (ZO1), a marker of epithelial tight junctions, on their basal aspect, suggesting changes in endometrial polarity. These IFNs apparently have no known antiluteolytic effects on CL, but they do stimulate secretion of PGE2 by the uterus.

Interactions between E2 and IFNs regulate celltype specific expression of multiple genes in the uterine endometrium that suggest a complex interplay between endometrium and conceptus for pregnancy recognition and implantation in pigs (see Ziecik et al., 2007; Bazer et al., 2008). In pigs, implantation is non-invasive and the placenta is epitheliochorial. Genes induced in LE by E2 include SPP1, FGF7, aldo-keto reducing family 1 member B1 (aldose reductase) (AKR1B1), cluster of differentiation 24 (CD24), neuromedin beta (NMB), STAT1 and IRF2 (reviewed in Johnson et al., 2009). IRF2, a potent inhibitor of transcription of ISGs, is induced in uterine LE of pigs by E2. Genes expressed in the presence of IRF2 are likely to have roles in establishment of pregnancy that include release of histotroph from uterine epithelia into the uterine lumen to affect cell proliferation, attachment and development of conceptus trophectoderm. In addition, IFND and IFNG may affect blastocyst attachment to LE by remodeling uterine epithelia to affect polarity and stimulate production of PGE2. Expression of IRF2 by porcine uterine LE/sGE prevents those cells from expressing classical ISGs; therefore, expression of ISGs is restricted to endometrial stroma and GE including STAT1, STAT2, IRF1, MX1, swine leukocyte antigens (SLA) 1-3 and 6-8, and beta 2 microglobulin (B2M; reviewed in Johnson et al., 2009). The pregnancyspecific roles of these ISGs are not known, but they may: 1) affect decidual/stromal remodeling to protect the fetal semi-allograft from immune rejection; 2) limit conceptus invasion into the endometrium; and/or 3) stimulate development of uterine vasculature. Because IFNG can initiate endometrial vascular development, conceptus-derived IFNG in pigs may facilitate vascular changes for hematotrophic support of developing conceptuses.

The roles of prostaglandins in the pig uterus during pregnancy remain to be clarified; however, inhibitors of prostaglandin synthesis are detrimental to establishment and maintenance of pregnancy (see Ziecik et al., 2007). Further, PGF and PGE2 are present in greater amounts in the uterine lumen of pregnant than cyclic gilts. There is evidence that PGF from the uterus is taken up by the mesometrium and transferred back to the uterus in arterial blood by a countercurrent system for conversion to its inactive metabolite, PGFM. Further, PGE2 synthase, PGF synthase, carbonyl reductase/prostaglandin 9-ketoreductase and PGE2 synthase:PGF synthase ratios are higher in CL of pregnant than cyclic gilts, but not between CL on ovaries ipsilateral and contralateral to the pregnant uterine horn. Therefore, compounds from the conceptus appear to be transported within the mesometrium to both ovaries to enhance CL maintenance and function. An integral part of the maternal recognition of pregnancy signaling events may involve the lipid signaling system consisting of PGF, PGE2 and lysophosphatic acid (LPA) with PGE2 synthase in trophoblast and endometrium decreasing PGF synthase and carbonyl reductase/prostaglandin 9-ketoreductase in conceptuses favoring PGE2 production to support uterine functions, CL maintenance and establishment and maintenance of pregnancy. Expression of LPA3 during pregnancy may affect establishment and maintenance of pregnancy in pigs as it is critical for embryo migration and spacing in mice and appears to be similarly important in pigs to enhance successful implantation and placentation (Seo et al., 2016).

Pig conceptuses secrete estrogens between days 10 and 15 for pregnancy recognition, but also to increase expression of growth factors such as IGFI and FGF7, which in turn act on the trophectoderm to stimulate cell proliferation and development (see Spencer et al., 2004; Bazer et al., 2008). IGFI is expressed by uterine glands of cyclic and pregnant pigs and IGF1 receptors (IGF1R) are expressed in endometrium and conceptuses, suggesting paracrine and autocrine actions of IGFI. FGF7, an established paracrine mediator of hormone-regulated epithelial growth and differentiation, is expressed by uterine LE and is most abundant between days 12 and 15 of the estrous cycle and pregnancy. FGF7 binds to and activates FGF2IIIb expressed by uterine epithelia and conceptus trophectoderm. E2 increases FGF7 expression and FGF7, in turn, increases cell proliferation, phosphorylated FGFR2IIIb, the mitogenactivated protein kinase cascade and expression of urokinase-type plasminogen activator, a marker for trophectoderm cell differentiation. From about day 20 of pregnancy, FGF7 is expressed by uterine GE in pigs and may continue to affect uterine epithelia and conceptus development (see Johnson et al., 2009).

During the period of rapid elongation, porcine conceptuses secrete estrogen beginning on days 11 and 12 to signal initiation of pregnancy to the uterus, and by day 13 begin an extended period of incremental attachment to the uterine LE. The attached trophectoderm/chorion-endometrial epithelial bilayer develops microscopic folds, beginning about day 35 of gestation, and these folds increase the surface area of 
contact between maternal and fetal capillaries to maximize maternal-to-fetal exchange of nutrients and gases (Dantzer, 1984). In addition to the increase in secretion of estrogens between days 11 and 15 of pregnancy for maternal recognition of pregnancy, concentrations of estrogens increase in fetal fluids and maternal blood between days 15 and 30, decrease to day 60 and then increase again between days 60 of gestation and term (114 days). The increase in estrogens between days 20 and 30 is associated with increases in expression of endometrial receptors for PRL, rapid accumulation of allantoic fluid, elongation of the chorioallantoic membranes during placentation and increased uterine blood flow. There are few descriptions of the hypertrophy and hyperplasia that the uterine GE of pigs undergo as GE increase production of histotroph, particularly between days 30 and 90 of pregnancy (Knight et al., 1977; Perry and Crombie, 1982). Endometrial GE development, or adenogenesis, begins during early postnatal life in pigs (Gray et al., 2001; Bartol et al., 2006). A series of elegant studies have implicated estrogen and relaxin as key mediators of early GE development in pigs (Bartol et al., 2006). The GE of non-pregnant adult pigs are lined by a low cuboidal epithelium that shows few adaptations to indicate high secretory activity (Perry and Crombie, 1982). However, the GE of day 17 pregnant pigs, while remaining low cuboidal, have increased rough endoplasmic reticulum and Golgi, suggesting synthesis of secretory products (Perry and Crombie, 1982). The GE remain simple, coiled and tubular through day 30 of pregnancy, but develop characteristics of increased secretory activity by day 35 when GE cells exhibit extensive rough endoplasmic reticulum with flocculentfilled cysternae. By mid-pregnancy, the lumens of uterine glands are greatly enlarged and filled with secretory products (Perry and Crombie, 1982). Between days 30 and 75 of gestation, placentation is completed and uterine gland activity is greatest in terms or transport of histotroph across the placental areolae into the fetal-placental circulation and accumulation in allantoic fluid. Uterine blood flow increases dramatically between days 35 and 100 of gestation along with increased uptake of amino acids and glucose across the uterus and inter-areolear areas of the placenta. Uterine and placental development are affected by E2, P4, PRL and RLX, but details of their individual effects in pigs are limited. However, PRL and P4 affect secretory activity of uterine GE and placental transport of nutrients in pigs (see Goldstein et al., 1976; Knight et al., 1977; Bazer et al., 1981;Young et al., 1990). In terms of mammogenesis and lactogenesis in pigs, E2, P4, PRL and possibly RLX affect mammogenesis between days 20 and 30, Stage I lactogenesis (around day 90) and Stage II lactogenesis (day 110) of the 114 day period of gestation (Kensinger et al., 1980).

\section{Pregnancy in mares}

\section{Estrous cycle and luteolysis}

Mares are seasonally polyestrous, with onset of cyclicity beginning in late winter in the Northern Hemisphere (see Irvine, 1995). Ovarian activity is inhibited by decreasing day length (photoperiod), but often lags several months after the solstice. The effects of photoperiod appear to be regulated by melatonin from the pineal gland. Mares typically exhibit estrous cycles of 21 to 22 days, although variability in length of estrus and diestrus is common, particularly during transition into and out of the breeding season. Mares have highest fertility between May and July; however, the goal is for mares to foal near January 1 (the arbitrary birth date for all foals in a given year). Estrus lasts from 3 to 7 days and is accompanied by swelling and reddening of the vulva in response to estrogens from ovarian follicles. Ovulation occurs after the oöcyte undergoes the first meiotic division, typically 24 to $48 \mathrm{~h}$ before the end of behavioral estrus. Ovulation is preceded by an increase and then decrease in concentrations of LH in serum over a period of up to 10 days. Multiple ovulations are not uncommon, but secondary ovulations typically occur within $48 \mathrm{~h}$ of the initial ovulation. Additional ovulations during the luteal phase have been reported, but the physiological basis for them has not been defined. Secretion of FSH and LH increase in parallel with the initial increase in follicular development during late estrus/early diestrus and a second increase during mid-diestrus.

Progesterone production begins about $24 \mathrm{~h}$ after ovulation and is maximal between days 6 and 1820 post-estrus. Concentrations of $\mathrm{P} 4$ range from 4 to 8 $\mathrm{ng} / \mathrm{ml}$ during diestrus, but decline rapidly at the end of diestrus in response to uterine release of PGF and luteolysis. The uterine endometrium releases luteolytic PGF, but neither the pattern of release required for luteolysis nor endocrine regulation of uterine production of luteolytic PGF are clearly established. However, cervical stimulation results in release of OXT via the Ferguson reflex and stimulates uterine secretion of PGF as does administration of exogenous OXT. It is assumed that the combined effects of P4, E2 and OXT are responsible for activation of the luteolytic mechanism in mares and the CL of mares are responsive to luteolytic effects of PGF after day 5 post-ovulation.

\section{Pregnancy}

The equine conceptus produces an unknown factor(s) that inhibits uterine release of luteolytic PGF (see Sharp et al., 1989). In cycling mares, concentrations of PGF in uterine venous plasma and uterine flushings increase between days 14 and 16 when luteolysis occurs and concentrations of $\mathrm{P} 4$ in plasma decline. PTGFR on luteal cells are abundant between day 14 of the estrous cycle and estrus, as well as day 18 of pregnancy. The equine conceptus migrates between the two uterine horns until fixation on day 18 of pregnancy to activate an antiluteolytic mechanism as amounts of PGF in uterine fluids and uterine venous plasma are reduced and PGFM in peripheral plasma is not released in a pulsatile pattern in pregnant mares. Further, the presence of the conceptus abrogates endometrial production of $\mathrm{PGF}$ in response to both 
cervical stimulation and exogenous OXT, indicating the absence of, or a reduction in, expression of endometrial OXTR in pregnant mares. Equine conceptuses produce increasing amounts of E2 between days 8 and 20 of gestation; however, attempts to prolong CL lifespan in mares by injections of E2 have yielded variable results. The equine conceptus also secretes proteins of 400, 65 and $50 \mathrm{kDa}$ between days 12 and 14 of pregnancy, as well as IFND (Tayade et al., 2008), but their role(s) in pregnancy recognition are not known.

\section{Pregnancy in rodents}

\section{Estrous cycle and luteolysis}

Laboratory rodents are nonseasonal, spontaneously ovulating, polyestrous mammals having estrous cycles of 4 to 5 days in length that includes proestrus (12 to $14 \mathrm{~h})$, estrus ( 25 to $27 \mathrm{~h})$, metestrus (6 to $8 \mathrm{~h}$ ) and diestrus (55 to $57 \mathrm{~h}$; see Freeman et al., 1974; Soares et al., 2007). For rats, mice and hamsters, the CL secrete P4 for two days, but become fully functional only after vaginal stimulation. The absence of a true luteal phase in non-mated rodents allows for recurrent estrous cycles of short duration and frequent opportunities for mating and establishment of pregnancy. During the estrous cycle of the rat, newly formed CL are maintained through metestrus of the following cycle and then regress due to apoptosis of luteal cells, degeneration of blood vessels, infiltration of leukocytes and increased aldo-keto reductase family 1 , member C1 (dihydrodiol dehydrogenase 1; 20-alpha (3alpha)-hydroxysteroid dehydrogenase; AKR1C1 also known as 20 $\alpha$-HSD) activity. Although PGF is luteolytic in rodents, its mechanism of action is not known. The CL of cyclic rodents secrete $\mathrm{P} 4$ which is rapidly metabolized by AKR1C1 to $20 \alpha$-hydroxy P4

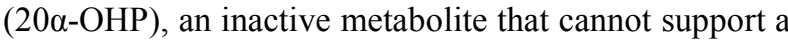
uterine decidual reaction for implantation or pregnancy. As secretion of luteal $20 \alpha-\mathrm{OHP}$ declines during diestrus, there is onset of proestrus and then estrus and ovulation.

\section{Pseudopregnancy and pregnancy}

The gestation period for rats, mice and hamsters is 20 to 22 days and functional CL must produce P4 through day 17 (see Soares et al., 2007). Thus, maternal recognition of pregnancy in rodents involves signaling for formation of functional CL that can produce $\mathrm{P} 4$ to support uterine decidualization, implantation and pregnancy. Sterile mating or cervical stimulation of rodents during estrus results in establishment of functional CL that secrete P4 for 12 to 14 days; a period known as pseudopregnancy. Extension of CL lifespan beyond day 12 requires the presence of viable conceptuses within the uterus. Establishment and maintenance of pregnancy requires two endocrine events. First, mating elicits diurnal and nocturnal surges of PRL from the pituitary that increase LH receptors on luteal cells for formation of $\mathrm{CL}$ and suppression of AKR1C1 (20 $\alpha$-HSD) activity in CL to prevent

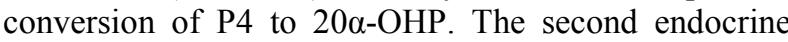

event required for maintenance of pregnancy beyond day 12 in rodents is dependent on implantation, conceptus development, and production of lactogenic hormones by uterine decidua and placentae. These members of the lactogenic family of hormones take over from pituitary PRL as luteotrophic hormones that act on $\mathrm{CL}$ to maintain production of $\mathrm{P} 4$ throughout gestation.

Interferons (IFNA, IFNB, IFNG) are produced by placentae of mice as early as day 7 of pregnancy and several ISGs are expressed by cells in implantation sites (Austin et al., 2003; Bany and Cross, 2006). Expression of both IFNA and interferon-regulated gene 1 (IRG1) increase in uteri of pregnant rats between days 1 and 4 and then decrease following implantation. Further, trophoblast giant cells express IFNA that induces expression of ISG15 during the peri-implantation period in mice. Microarray analyses revealed up-regulation of ISGs, as well as down-regulation of genes for histocompatibility 2, T region locus 23, IRF6, and MHC Class I and Class II at implantation sites in mice. Expression of IFNB also increases at implantation sites when estradiol is used to induce implantation, and IFNG is expressed by uterine LE and GE, trophoblast cells and degenerating metrial gland cells of mice. However, most IFNG in decidua of mice at mid-gestation is from uterine NK cells which effect changes in uterine spiral arteries. Thus, Type I and Type II interferons likely modify gene expression at implantation sites in rodents to directly affect conceptuses or to exert indirect effects on blood vessels and decidual cells.

\section{Rodent decidual PRL-like proteins and placental lactogens}

Implantation in rodents involves P4-dependent transformation of stromal cells into decidual cells which are small, loosely packed fibroblast-like and binucleate cells. The decidual cells produce PRL, alpha-2macroglobulin and growth factors, while the antimesometrial decidua formed by giant polyploid cells secrete hormones that include follistatin, activin, transforming growth factor beta, and several PRL family proteins including PRL-like protein B (PLPB) and decidual PRL-like protein (dPRP; Soares et al., 2007). Hormones produced by the antimesometrial decidua sustain luteal production of P4 and inhibit aromatization of androgens to estradiol by ovarian follicles ( $\mathrm{Gu}$ et al., 1995). The main luteotropic hormone of the decidua is PRL that maintains secretion of P4. The dPRP also binds receptors on mesometrial decidual cells and up-regulates expression of alpha-2macroglobulin. Various forms of lactogenic hormones are produced by placentae of rodents, but primary roles of CSH1 are: 1) maintenance of P4 secretion by CL during pregnancy; 2) development of the mammary gland during pregnancy; and 3) control of maternal metabolic functions. Various isoforms of placental lactogens and PRL, along with P4, E2, corticosteroids, insulin and $\mathrm{GH}$ are also responsible for adipogenesis, glucose and lipid metabolism, as well as mammogenesis and lactogenesis (Soares et al., 2007; Ben-Jonathan et al., 2008). The lactogenic hormones in rodents exert 
effects on the maternal immune system, hematopoiesis, angiogenesis, and metabolism during pregnancy (Soares et al., 2007). In rodents, RLX increases elasticity of ligaments of the pelvis and connective tissue of the cervix to facilitate parturition and stimulate growth of the nipples of the mammary glands to allow pups to suckle (Sherwood, 2004)

\section{Pregnancy in humans and other primates}

\section{The menstrual cycle}

The mechanism(s) responsible for luteolysis in primates is not established (Stouffer, 1988). Estradiol may act directly on luteal cells of primates to initiate luteolysis or suppress LH required for luteal maintenance, but this estradiol-mediated luteolyic pathway is controversial. Similarly, PGF may act directly on primate CL to initiate luteolysis as inhibitors of PGF synthesis do not extend CL lifespan, whereas intraluteal infusion of PGF, but not other prostaglandins, causes premature luteolysis in monkeys. Therefore, PGF may be an intra-ovarian hormone that acts in concert with other intra-ovarian peptides/proteins to cause luteolysis of CL in primates. Nevertheless, CL regression is clearly uterine-independent as hysterectomy does not alter cyclic ovarian function in either women or monkeys.

\section{Pregnancy}

Maternal recognition of pregnancy signaling extends CL function throughout pregnancy or until the time of the luteal-placental shift when production of P4 by the placenta is adequate to support pregnancy (Fazleabas et al., 2004). Primate embryos enter the uterus on days 3 or 4 post-ovulation at the morula stage, develop into hatched blastocysts, and begin implantation to uterine LE on days 7 to 9 post-ovulation in macaques and humans or days 11 to 12 in marmoset monkeys. CGB produced by primate blastocysts signals maternal recognition of pregnancy through its luteotrophic actions via LHCGR on luteal cells. Circulating concentrations of $\mathrm{CGB}$ are first detected around the time of implantation in primates, increase to peak values in the first trimester and then decrease during late gestation in humans. However, circulating levels are at or near the limits of detection by midpregnancy in some primates and do not peak in others until mid-pregnancy and decline just before parturition in other species. In rhesus monkeys, "rescue" of the CL occurs on day 9 post-ovulation when CGB is detectable in utero-ovarian venous blood, but not peripheral blood. There is evidence for CGB mRNA in 8-cell human embryos and hatched blastocysts of the rhesus monkey and LHCGR in primate endometria. Production of CGB by human trophoblast may be regulated by gonadotropin-releasing hormone 1 (luteinizing-releasing hormone; GNRH1) from the uterus as gonadotropinreleasing hormone receptors (GNRHR) are detectable in placental tissue, or inhibin, activin and P4 from the ovary and/or placenta. Importantly, GNRH agonists enhance and GNRH antagonists suppress CGB secretion. Primate blastocysts also produce inhibin and steroids which may affect $\mathrm{CGB}$ secretion. In many primates, CGB production decreases during the lutealplacental shift in $\mathrm{P} 4$ production. Both passive and active immunization of primates with modified forms of CGB result in infertility, but do not prevent primates from continuing normal menstrual cycles. Further, exogenous CGB increases P4 production and extends CL lifespan in women and monkeys. Thus, CGB alone appears to be the maternal recognition of pregnancy signal in nonhuman primates and in humans.

There are other aspects of uterine receptivity to implantation and pregnancy in humans (see Fazleabas et al., 2004). First, PGR are limited to endometrial decidual tissue which is responsive to P4. Second, CGB acts via LHCGR on uterine epithelial and stromal cells to induce decidualization of stromal cells which: 1) secrete PRL and IGFBP1; 2) increase edema; 3) express alpha smooth muscle actin and PTGS2; 4) increase angiogenesis and blood flow; and 5) express leukemia inhibitory factor (LIF). Interleukin 1 beta (IL1B) from the trophoblast also increases expression of IGFBP1 and decidualization of endometrial stromal cells. During the window of implantation in humans, P4 stimulates development of uterine glands and secretory activity by GE and down-regulates ESR1 in uterine epithelia. Thereafter, ESR1 and PGR are restricted to the basalis zone of the endometrium prior to implantation while PGR remain abundant in uterine stromal cells. The window of implantation in humans is characterized by expression of integrin heterodimers $\alpha_{1} \beta_{1}, \alpha_{4} \beta_{1}$ and $\alpha_{v} \beta_{3}$, which can bind fibronectin, vitronectin, thrombospondin, von Willebrand factor, bone sialoprotein 1, and SPP1. Binding of L-selectin to $\alpha_{4} \beta_{1}$ is associated with establishment of connections between invading conceptus trophectoderm and maternal vasculature that extends to placentation, while $\alpha_{\mathrm{v}} \beta_{3}$ and SPP1 complexes localize to pinopods of endometrial LE to serve as a marker of implantation. Glycodelin from uterine glands may facilitate implantation, but LIF and calcitonin are required for implantation from work in mice.

Secretions from uterine GE increase in response to $\mathrm{P} 4$, likely acting via PGR in stromal cells that express progestamedins such as FGF7, FGF10 and HGF (Slayden and Keater, 2007). Proteins in these secretions include uteroglobin, histone A2, spermidine/spermine acetyltransferase 2, secretory leukocyte protease inhibitor and metallothionine. Stromal cells of humans and macacques also secrete proprotein convertase 6 (PC6) at the implantation site. However, P4 suppresses expression of transforming growth factor beta (TGFB), matrix metalloproteinase 11, proenkephalins, cysteine/glycine rich protein 2, collagen type $\mathrm{VII}_{\alpha 1}$ and frizzle related protein 4 , while FGF7 has anti-apoptotic effects on uterine GE.

Human extravillous and villous trophoblast from first and third trimester human pregnancies produce IFNA and IFNB that may: 1) regulate proliferation of trophoblast or uterine cells; 2) exert immunosuppressive effects by suppressing mitogen- 
induced proliferation of $\mathrm{T}$ - and $\mathrm{B}$-cells; 3 ) protect the conceptus from viral infections; 4) regulate cellular differentiation and expression of cell surface antigens; 5) stimulate expression of $\varepsilon$-globin, a component of embryonic hemoglobin; and 6) suppress expression of proto-oncogenes such as epidermal growth factor receptors (EGFR) and colony stimulating factor 1 receptor (CSFR1) to affect trophoblast growth and differentiation (Aboagye-Mathiesen et al., 1995). ISGs upregulated in human endometrial stromal cells treated with human trophoblast conditioned medium include: DDX58, GBP1, GBP2, HSXIAPF1, IFIH1, IFIT1, IFIT2, IFIT3, IFIT5, IFI35, IRF1, ISG15, MIC, MX1, MX2, NMI, OAS1, OAS2, OAS3, PLSCR1, RSAD2, RTP4, SERPING1, STAT1, and STAT2 (Hess et al., 2007). During the peri-implantation period of pregnancy, increases in B2M, GBP1, IFI27, IRF1, and ISG15 occur in endometria of humans, baboons, domestic animals, and laboratory animals. Guanylate binding protein 1 (GBP1), a GTPase, is a marker of uterine receptivity to implantation, but its function is unknown. Myxovirus resistance 1 proteins (MX1) as well as GTPases, may protect against viral infection. The shift in endometrial production from PGF to PGE is associated with implantation in humans and may be due to actions of IFNA that suppress P4-regulated production of PGF but not PGE2 in ruminants.

The luteal-placental shift in production of $\mathrm{P} 4$ from $\mathrm{CL}$ to placenta is accompanied by increases in CGB secretion stimulated by $\mathrm{GnRH}$, epidermal growth factor, activin, interleukin 1 (IL1) and IL6, macrophage colony stimulating factor, $\gamma$-aminobututyric acid, retinoic acid, glucocorticoids and dihydroepiandrosterone, but inhibited by transforming growth factor beta, dopamine, inhibin, P4, IGF1, testosterone and estrogens. The placentae of primates can produce all hormones of the hypothalamic-pituitarygonadal axis which regulate $\mathrm{LH}$ and FSH secretion, as well as production of P4, estrogens, CSH1 and RLX during gestation. An excellent review of these hormones with emphasis on CGB, PRL and CSH1 has been published (Ben-Jonathan et al., 2008). The major points from that review are summarized the following sections.

During the first trimester of pregnancy, PGR are expressed by uterine decidual cells and uterine GE express abundant receptors for LHCGR. CGB is a luteotrophin, but it also stimulates expression of PTGS2 by uterine epithelia. Receptors for PRL are also expressed by uterine GE and decidualized stromal cells during early pregnancy. Long-term exposure of uterine GE to P4 stimulates decidual cells via the PGR to secrete PRL and syncytiotrophoblast to secrete CSH1. Both PRL and CSH1 stimulate uterine GE, in concert with CGB, to regulate the secretory activity of uterine GE that supplies nutrients and other factors to the conceptus (Burton et al., 2007). In addition, local paracrine signals within the decidua influence accumulation of natural killer (NK) immune cells in the vicinity of uterine GE during early pregnancy. The NK cells secrete a variety of cytokines when activated, as well as epidermal growth factor (EGF). Thus, interactions between extravillous trophoblast and NK cells may signal the presence of a conceptus to the endometrial GE in humans and other primates. Deficiencies in uterine GE secretions may result in early pregnancy failure. The uterine glands secrete glycodelin $\mathrm{A}$ and MUC1, both of which are lower in women who fail to maintain pregnancy. Failure to secrete adequate amounts of these key proteins may result from failure of uterine GE to down-regulate PGR in women with a luteal phase defect. At present, it is not known if miscarriages result from development of an incomplete cytotrophoblast shell due to inadequate EGF-induced proliferation or abnormal immunological interactions within decidual cells through a lack of modulation by glycodelin A.

There is no evidence that either PRL or CSH1 is luteotrophic for primate CL. Rather, pituitary LH and CGB are responsible for development and maintenance of $\mathrm{CL}$ for production of $\mathrm{P} 4$ required for pregnancy. However, from mid-pregnancy to term, the human placenta is the primary source of P4 and estrogens. The human uterine decidua produces PRL during pregnancy, but its functions with respect to decidual tissue or chorioamnion are not established. However, PRL and CSH1 affect transport mechanisms for water, electrolytes and nutrients across the chorioamnion (see Bazer et al., 1981), and PRL stimulates production of prostaglandins and fetal lung development. PRLR are expressed by decidual cells, chorionic cytotrophoblast, amniotic epithelium and syncytiotrophoblast. Secretion of $\mathrm{CSH} 1$ and $\mathrm{GH}$ by human placentae is highest between weeks 6 and 30 of gestation. CSH1 increases appetite and food intake, glucose uptake, increases insulin secretion, insulin sensitivity and lipolysis for mobilization and utilization of maternal free fatty acids.

\section{Uterine response to pregnancy recognition signals: temporal and cell-specific effects}

\section{Servomechanism}

Studies on the role of IFNT in pregnancy identified a servomechanism for maintenance of pregnancy that requires reciprocal communication between the conceptus and endometrium during implantation and during synepitheliochorial placentation in ewes (Spencer et al., 1999, 2007; Stewart et al., 2000, 2001; Noel et al., 2003). This concept derived from our studies to determine if the antiluteolytic effects of IFNT to extend lifespan of CL are reinforced by effects of placental lactogen (CSH1) and/or placental growth hormone (GH1) secreted from day 15 to term, and days 35 to 65 of pregnancy, respectively. Neither independent nor interactive effects of CSH1 and GH1 on luteal maintenance and function in ewes were detected, but both $\mathrm{CSH} 1$ and GH1 affected development and function of uterine glands (Spencer et al., 1999). Interestingly, this response required that the uterus be exposed to intra-uterine IFNT between days 11 and 21 and then to intra-uterine $\mathrm{CSH} 1, \mathrm{GH} 1$ or $\mathrm{CSH} 1$ and $\mathrm{GH} 1$ between days 16 and 29 after onset of estrus. During gestation, endometrial gland hyperplasia occurs between days 15 and 50 of pregnancy and that is followed by 
hypertrophy of the uterine glands to increase surface area for maximal production of histotroph after day 60 of pregnancy (Spencer et al., 2007). Sequential exposure of the ovine endometrium to E2, P4, IFNT, $\mathrm{CSH} 1$ and GH1 constitutes a "servomechanism" responsible for sequential actions of these respective hormones to activate and maintain endometrial remodeling, secretory function and uterine growth during gestation (Spencer et al., 2007). Down-regulation of epithelial PGR is a prerequisite for P4-induced expression of genes in uterine GE that include SPP1, UPTI (uterine plasmin trypsin inhibitor) and STC1/STC2 (stanniocalcin). Treatment with a combination of $\mathrm{P} 4$ and E2 increases expression of ESR1 and PGR in uterine GE which inhibits expression of SPP1 and UPT1. Thus, undefined actions of IFNT are prerequisite to a developmentally programmed sequence of events, mediated by specific paracrine-acting factors at the conceptus-endometrial interface that stimulate both intercaruncular endometrial remodeling and differentiated functions of uterine GE to increase production of histotroph for fetal-placental growth during gestation.

\section{Expression of nutrient transporters}

Interferon tau abrogrates the uterine luteolytic mechanism, but of equal importance is it acts cooperatively with progesterone $(\mathrm{P} 4)$ to stimulate expression of many genes referred to as P4-induced and IFNT-stimulated genes by uterine LE/sGE that lack both PGR and STAT1 (see Bazer et al., 2009b). Those gene products are critical for uterine receptivity to implantation and conceptus development. The genes include transporters for glucose (SLC2A1) and and cationic amino acids like arginine (SLC7A1). The energy substrate for mammalian conceptuses switches from pyruvate to glucose at the blastocyst stage in concert with increases in expression of uterine glucose transporters. In ovine uteri, total recoverable glucose increases 12 -fold between days 10 and 15 of pregnancy, but not the estrous cycle. Correspondingly, SLC2A1 mRNA and protein increase in ovine uterine LE/sGE 7.2-fold between days 10 and 14 of pregnancy and remain elevated thereafter, whereas SLC2A3 is expressed only in conceptus trophectoderm. In ovariectomized ewes, GLUT1 mRNA increased 4.2fold in response to $\mathrm{P} 4$ and an additional 2.1-fold in response to IFNT. The cationic amino acid transporter, $\mathrm{y}+$ system, member 2 (SLC7A2) is $60 \%$ similar to SLC7A1and both are members of the amino acid, polyamine, choline family of transporters expressed by many tissues. In ewes, total recoverable arginine increases significantly between days 10 and 15 of pregnancy, but not the estrous cycle. Correspondingly, SLC7A2 mRNA in uterine LE/sGE and stromal cells is most abundant between days 14 and 20 of pregnancy. In ovariectomized ewes, P4 induced and IFNT stimulated expression of SLC7A2 mRNA in uterine epithelia.

Nutrients in uterine secretions are essential for development and survival of conceptuses; therefore, we determined amounts of amino acids in uterine fluids of cyclic and pregnant ewes (Gao et al., 2009b). There are significant effects of day of pregnancy on amounts of amino acids in uterine flushings from ewes and pigs. These results indicate activation of pregnancyassociated mechanisms for transport of amino acids into the uterine lumen, and provide a framework for studies of amino acids required to activate nutrient sensing cell signaling pathways for growth, development and survival of conceptuses, as well as for optimization of culture media for in vitro studies of conceptus development.

The abundance of Arg, Gln and Leu in the ovine uterine lumen increases markedly during early pregnancy, but not during the luteal phase of the estrous cycle. Concentrations of these amino acids in uterine fluids (0.46-0.80 mM Arg, 1.2-1.4 mM Gln, 0.22-0.30 $\mathrm{mM}$ Leu on days 15 and 16 of gestation) are greater than in maternal plasma (Gao et al., 2009b). The amounts of Arg, Gln and Leu are 7-, 6- and 5-fold greater, respectively, in ovine uterine flushings from day 15 of pregnancy compared to day 15 of the estrous cycle. Increases in amounts of these amino acids between days 10 and 16 of gestation coincide with rapid growth and development of conceptuses during the periimplantation period. These three amino acids likely play crucial roles in embryonic survival and development. First, Arg, Gln and Leu are abundant in proteins of animal cells and in physiological fluids of the conceptus (Wu et al., 2013a, c). Second, differential effects of Arg, Gln and Leu on hypertrophy and hyperplasia of cells are important for peri-implantation conceptus development. As noted previously, Arg, Gln and Leu stimulate MTOR cell signaling to activate its target RPS6 to induce cell proliferation and mRNA translation (Wynn and Wynn, 1988). The cellular responses include hyperplasia and hypertrophy for conceptus elongation in ruminants (Guillomot et al., 1993). Third, motility and outgrowth of trophectoderm required for implantation can be stimulated by Arg and Leu via MTOR cell signaling in mice (Martin and Sutherland, 2001; Martin et al., 2003) and sheep (Kim et al., 2010). Fourth, Gln metabolism in the conceptus provides reducing equivalents for ATP production (Rieger et al., 1992; Wales and Du, 1994) possibly to compliment glucose metabolism (Gardner et al., 1993). Finally, Arg is nutritionally essential for fetalplacental growth and development via its role in NO signaling and polyamine synthesis, as well as insulin secretion and insulin-mediated anabolic effects (Gresores et al., 1997; Thureen et al., 2002; Jogben et al., 2006; Wu et al., 2007a, b).

\section{Key roles for select nutrients transported into the uterus and conceptus}

Arginine

Nitric oxide (NO) and polyamines (putrescine, spermidine, and spermine) are products of Arg catabolism that are critical for placental growth $(\mathrm{Wu}$ et al., 2009). Arginine stimulates placental NO production by enhancing expression of GTP cyclohydrolase I (GCH1), the first and rate-controlling enzyme for synthesis of tetrahydrobiopterin (BH4, an essential 
cofactor for all isoforms of NO synthase). Additionally, glutathione, synthesized from glutamate, glycine and cysteine, is the major antioxidant in the conceptus (Wu et al., 2009). Transport of amino acids requires multiple specific transporters (Grillo et al., 2008). Intra-uterine growth restriction (IUGR) of porcine fetuses is associated with impaired transport of basic, neutral and acidic amino acids by the placenta (Regnault et al., 2002; $\mathrm{Wu}$ et al., 2008). Thus, maternal protein nutrition greatly impacts embryonic/fetal survival in pigs (Pond et al., 1969; Pond and $\mathrm{Wu}, 1981)$. Along with insulin-like growth factors, vascular endothelial growth factor and other growth factors, $\mathrm{NO}$ and polyamines are crucial for angiogenesis, embryogenesis, placental growth, uteroplacental blood flow, and transfer of nutrients from mother to fetuses, as well as fetal-placental growth and development (Wu et al., 2006; Wu and Meininger, 2009).

We discovered an abundance of Arg in porcine allantoic fluid during early gestation (Wu et al., 1995, 1996). Arginine and ornithine account for 50 and 55\% of the total alpha amino-acid nitrogen (the sum of nitrogen in $\alpha$-amino acids) in porcine allantoic fluid on days 40 and 45 of gestation, respectively. Similarly, members of the Arg family of amino acids are highly abundant in ovine allantoic fluid (e.g., $10 \mathrm{mM}$ citrulline and $25 \mathrm{mM}$ Gln on day 60 of gestation; Kwon et al., 2003). The ovine placenta expresses arginase and degrades arginine; therefore, citrulline is abundant in allantoic fluid to conserve arginine, whereas the pig placenta does not express arginase, which allows for the transfer of arginine from mother to fetus and the accumulation of arginine in allantoic fluid. These observations indicate different strategies for arginine metabolism among gestating mammals and suggested important biological roles for Arg in growth and development of mammalian conceptuses. Accordingly, rates of $\mathrm{NO}$ and polyamine synthesis in both porcine and ovine placentae are highest during early gestation when placental growth is most rapid (Kwon et al., 2004a, b; Wu et al., 2005, 2012). We hypothesize that impaired placental growth (including vascular growth) or function results from reduced placental synthesis of $\mathrm{NO}$ and polyamines, thereby contributing to IUGR in both underfed and overfed dams (Wu et al., 2006). Growing evidence from studies with pigs, sheep, and rats supports this hypothesis (Wu et al., 2013a, b, c; Li et al., 2014).

Arginine stimulates hypertrophy, hyperplasia and differentiation of ovine conceptus trophectoderm cells. Therefore, signaling pathways mediated by Arg to effect proliferation of ovine trophectoderm (oTr) cells were assessed using NO donors (SNAP and DETA) and putrescine (a precursor for spermidine and spermine; Kim et al., 2011). L-NAME (an inhibitor of NOS) and Nor-NOHA (an inhibitor of arginase) were also used to assess pathways activated via Arg. Both NO donors and putrescine enhanced cell proliferation in a dosedependent manner and effects of Arg were partially inhibited by both L-NAME and Nor-NOHA. These results indicate that Arg enhances production of polyamines and NO that activate MTOR/FRAP1RPS6K-RPS6 cell signaling to stimulate proliferation and migration of oTr cells. Consistent with activation of these cell signaling molecules, Arg increased protein synthesis and reduced protein degradation in oTr cells. It has also been reported that porcine trophectoderm (pTr2) cells respond to $10,50,100,200,350$, or $500 \mu \mathrm{m}$ Arg with dose-dependent increases in proliferation (Kong et al., 2012; Kim et al., 2013). Further, 100 and $350 \mu \mathrm{m}$ Arg in culture medium dose-dependently increased protein synthesis, decreased protein degradation, and increased the abundance of total and phosphorylated MTOR, p70S6K, and 4EBP1 proteins in pTr2 cells. It is also of interest that arginine was depleted (utilized) from medium in which conceptuses from days 14-16 bovine conceptuses were cultured, with arginine depletion being greatest for day 14 as compared to days 15-16 conceptuses (Morris et al., 2002), which is consistent with a decrease in rate of protein synthesis during that period (Morris et al., 2000). Available results indicate a novel and important role for Arg in promoting growth of pTr2 cells and mammalian conceptuses that helps to explain beneficial effects of Arg supplementation on improving survival and growth of embryos/fetuses in mammals (Fig. 3).

The unusual abundance of arginine in porcine allantoic fluid during early pregnancy and its important physiological functions in survival and growth of the conceptus (see Wu et al., 1996) led to a study by Mateo et al. (2007) to determine the effects of dietary supplementation of arginine on reproductive performance of pregnant gilts. Dietary supplementation with $0.83 \%$ arginine (as $1.0 \%$ arginine- $\mathrm{HCl} ; 16.6 \mathrm{~g}$ arginine/sow per day) between days 30 and 114 of gestation increased the number of live-born piglets by 2 per litter and litter birth-weight by $24 \%$ (Mateo et al., 2007). The rationale for supplementing the diet of pregnant gilts with $0.83 \%$ arginine (as $1 \%$ arginine$\mathrm{HCl})$ to the basal diet $(12 \%$ crude protein, $0.70 \%$ arginine, and $0.57 \%$ lysine; a digestibility value of $85 \%$ ) is based on arginine kinetics and concentrations in plasma (see Wu et al., 2013c).

Several lines of experimental evidence further support the conclusion that arginine supplementation is effective in enhancing embryonic/fetal survival in pigs. First, under practical production conditions, gilts that received dietary supplementation with $0.83 \%$ arginine between days 22 and 114 of gestation produced conceptuses with greater placental weights $(16 \%)$, an increase in live-born piglets per litter (1.1), and an increase in litter birth weights for live-born piglets of $1.7 \mathrm{~kg}$ (Gao et al., 2012). Second, under practical production conditions, dietary supplementation with $1 \%$ arginine to gilts and sows between days 14 and 28 of gestation increased the number of live-born piglets by approximately 1 (Ramaekers et al., 2006; Campbell, 2009). Third, as compared with control gilts, dietary supplementation with 0.4 or $0.8 \%$ L-arginine between days 14 and 25 of gestation increased placental weights $21-34 \%$ and number of viable fetuses per litter by approximately 2 (Li et al., 2010). Fourth, supplementation with $1 \%$ arginine between days 14 and 28 of gestation increased the number of fetuses per litter by 3.7 on day 70 of gestation in superovulated gilts (Bérard and Bee, 2010). Fifth, supplementing 1\% 
arginine to gilts beginning on day 17 of gestation for 16 days increased the number of live-born piglets per litter by 1.2 (De Blasio et al., 2009). Finally, dietary supplementation with $0.83 \%$ arginine between days 90 and 114 of gestation increased average birth weight of live-born piglets by $16 \%$ (Wu et al., 2012). An increase in the number of live-born pigs markedly increases the profit margin associated with reproduction and lactation performance in dams. There were also fewer low-birthweight piglets which greatly improves the management of neonatal pigs and maximizes pre-weaning survival and growth (Wu et al., 2010, 2011a, b).

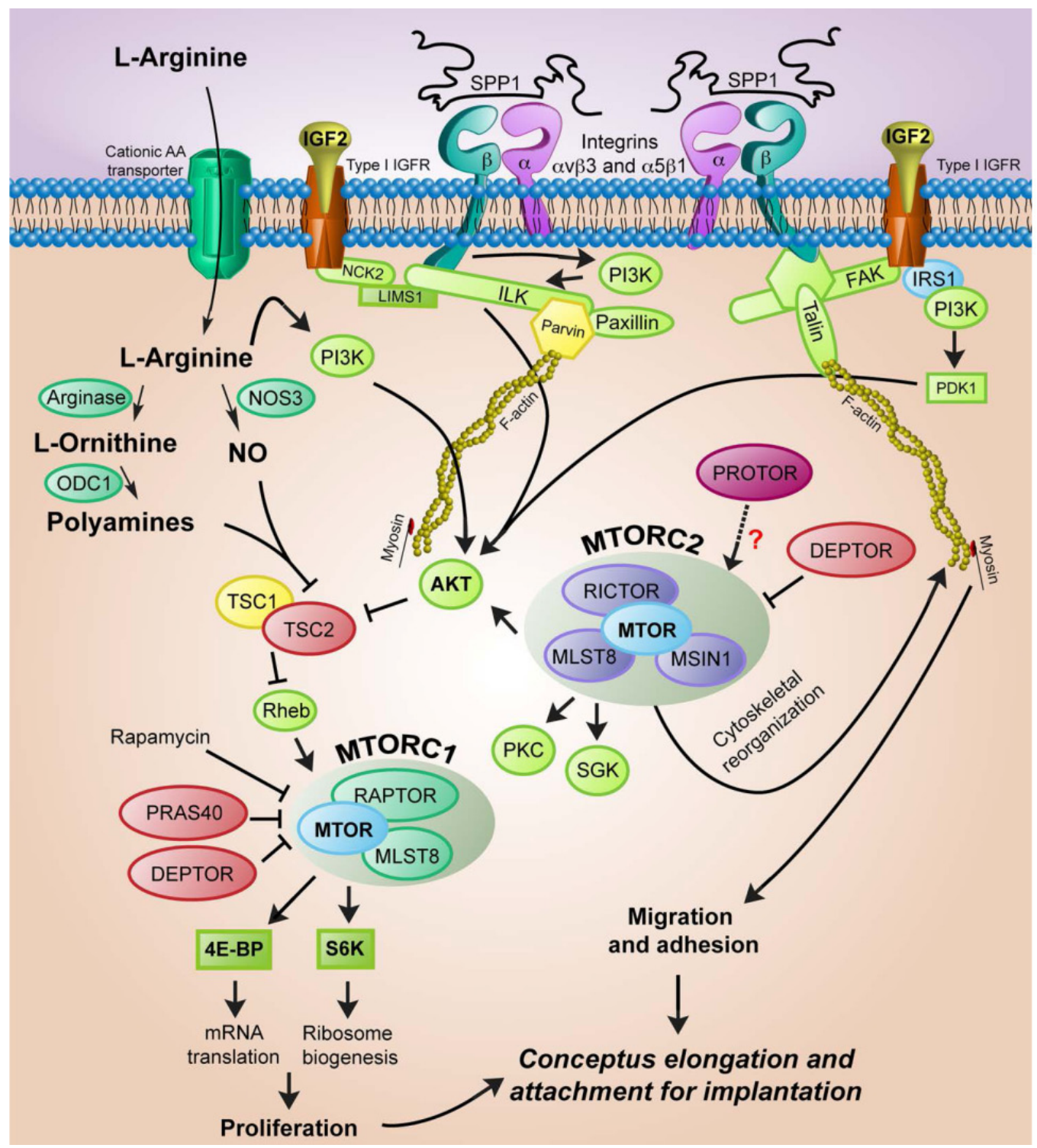

Figure 3. Arginine and secreted phosphoprotein 1 induce cell signaling for proliferation, migration, adhesion, and cytoskeletal remodeling of the ovine conceptus via the MTORC1 and MTORC2 cell signaling. Arginine and secreted phosphoprotein 1 (SPP1; also known as osteopontin) activate mechanistic target of rapamycin (MTOR) cell signaling via pathways that converge on AKT1 and MTOR via MTORC1 (cell proliferation and gene expression) and MTORC2 (cell migration, adhesion and cytoskeletal reorganization) to affect oTr cells in conceptuses for transition from spherical to tubular and filamentous forms that can signal pregnancy recognition, as well as undergo implantation and placentation. AKT1, proto-oncogenic protein kinase 1; FAK, focal adhesion kinase; PDK1, phosphoinositide-dependent protein kinase 1; MTOR, mechanistic target of rapamycin; RAPTOR, regulatoryassociated protein of MTOR; RICTOR, rapamycin-insensitive companion of MTOR; IGF2, insulin-like growth factor 2; type I IGF2, type I insulin-like growth factor receptor; ILK, integrin-linked kinases; IRS1, insulin receptor substrate 1; PKC, protein kinase C; SGK, serum/glucocorticoid-regulated kinase; MLST8, mammalian lethal with SEC13 protein 8; PRAS40, proline-rich Akt/PKB substrate $40 \mathrm{kDa}$; DEPTOR, DEP domain-containing MTORinteracting protein; MSIN1, mammalian stress-activated MAP kinase interacting protein 1; PROTOR, protein observed with RICTOR; NCK2, non-catalytic region of tyrosine kinase, beta; NO, nitric oxide; NOS3, nitric oxide synthase 3; ODC1, ornithine decarboxylase; PI3K, phosphatidylinositol 3-kinase; LIMS1, LIM and senescent cell antigen-like domains 1; S6K, S6 kinase; SPP1, secreted phosphoprotein 1 (see Bazer et al., 2015; Wang et al. 2016). 
The timing and dose of arginine supplementation are critical to its beneficial effects in improving pregnancy outcomes in swine (Wu et al., 2010). Specifically, as compared with the control group of gilts, those animals receiving a dietary supplementation of $0.8 \% \mathrm{~L}$-arginine between days 0 and 25 of gestation had decreased: 1) uterine weights ($20 \%) ; 2$ ) total number of fetuses $(-24 \%) ; 2$ ) numbers of corpora lutea $(\mathrm{CL} ; 17 \%) ; 3)$ total fetal weight $(34 \%) ; 4)$ total volume of allantoic and amniotic fluids (34 to $42 \%$ ); and 5) concentrations of progesterone in maternal plasma (33\%). In addition, there was a decrease in total amounts of progesterone $(35 \%)$, estrone $(40 \%)$, and estrone sulfate (37\%) in allantoic fluid (Li et al., 2010). In the ovary, follicular development and discharge of mature oocytes with the formation of CL depends on cell signaling via mitogen activated protein kinases 3 and 1 [also known as extracellular-regulated protein kinases 1 and 2 (ERK1/2); Duggavathi and Murphy, 2009] and liver receptor homolog 1 (Lrh1; Duggavathi et al., 2008). There is evidence that Lrh1 is essential for ovulation in mice through a mechanism involving expression of NOS3 (Johnson et al., 2009). Available results suggest that increased production of NO through arginine supplementation may impair ERK1/2 signaling and Lrh1 function in the porcine ovary, thereby reducing the number of follicles that ovulate and the number of CL, as well as concentrations of progesterone in maternal plasma. Regression of CL rarely occurs in pregnant pigs under normal feeding conditions and CL are the only known source of progesterone required for establishment and maintenance of pregnancy in pigs (Bazer et al., 2009b, c). Prostaglandin F2a (PGF), the luteolytic agent responsible for $\mathrm{CL}$ regression, is secreted from the uterine epithelia into the uterine circulation (endocrine secretion) during the estrous cycle, but into the uterine lumen (exocrine secretion) during pregnancy (Bazer and Thatcher, 1977). Thus, PGF production is modulated by estrogens secreted by the conceptus (Bazer and Thatcher, 1977). NO can also stimulate this biochemical event by up-regulating expression of prostaglandin synthase (PTGS2), a key enzyme for prostaglandin synthesis (Salvemini et al., 1993; Roberto da Costa et al., 2008). Thus, dietary Larginine supplementation, which promotes systemic NO synthesis in animals (Wu et al., 2010), may lead to CL regression through a PGF-dependent pathway. Additionally, because ovulation in swine usually takes place at about $44 \mathrm{~h}$ after onset of estrus (Bazer et al., 2012a, b), initiation of L-arginine supplementation within $24 \mathrm{~h}$ after onset of estrus may directly or through one of its metabolites, inhibit or interfere with follicular development, estrogen synthesis by follicles or ovulation, to decrease the number of CL in gilts.

Arginine and its immediate precursor (citrulline) are abundant in ovine uterine fluid (Gao et al., 2009b) and allantoic fluid (Kwon et al., 2003) during early to mid-gestation, and intravenous administration of arginine improves embryonic survival in pregnant ewes (Luther et al., 2008). We therefore tested the hypothesis that increasing utero-placental blood flow by administering 0,75 , or $150 \mathrm{mg} /$ day sildenafil citrate (Viagra) from days 28 to 115 of gestation to underfed $(50 \%$ of National Research Council (NRC) requirements) or adequately fed ewes (100\% of NRC requirements) enhanced fetal growth in ewes (Satterfield et al., 2010). On day 115, concentrations of amino acids and polyamines in maternal plasma and conceptuses were lower in underfed than adequately-fed ewes. However, treatment of ewes with Viagra increased: 1) amino acids and polyamines in amniotic and allantoic fluids and fetal serum; and 2) fetal weights in underfed ewes without affecting maternal body weights (Satterfield et al., 2010). Likewise, intravenous administration of arginine prevents IUGR in underfed ewes (Lassala et al., 2010). In this study, Suffolk ewes were fed a diet providing 100 or $50 \%$ (underfed) of NRC nutrient requirements, beginning on day 28 of gestation. Between day 60 of gestation and parturition, underfed ewes received intravenous infusions of saline or $155 \mu \mathrm{mol} \mathrm{L}$-arginine per kg body weight three times daily, whereas control ewes $(100 \%$ NRC) received saline. The birth weights of lambs from saline-infused underfed ewes were 23\% lower than those of lambs from control-fed dams (Lassala et al., 2010). The administration of arginine to underfed ewes increased concentrations of arginine in maternal plasma (69\%), fetal brown adipose tissue mass (48\%), and birth weights of lambs by $21 \%$, as compared to saline-infused underfed ewes (Satterfield et al., 2012). Similar results were observed for diet-induced obese ewes (Satterfield et al., 2012). Furthermore, intravenous administration of arginine (345 $\mu \mathrm{mol}$ arginine- $\mathrm{HCl}$ per $\mathrm{kg} \mathrm{BW}$ three times daily) between days 100 and 121 of gestation reduced the percentage of lambs born dead by $23 \%$, increased the percentage of lambs born alive by $59 \%$, and enhanced birth weights of quadruplets by $23 \%$, without affecting maternal body weight (Lassala et al., 2011). The beneficial effects of maternal arginine supplementation on pregnancy outcomes in sheep have been confirmed by other investigators (McCoard et al., 2016).

There is also evidence that dietary supplementation of pregnant rats with arginine increases the numbers of implantation sites and litter size by approximately three (Zeng et al., 2008, 2012). When compared with isonitrogenous control rats $(2.2 \% \mathrm{~L}-$ alanine), litter size in rats was increased in response to dietary supplementation with $1.3 \%$ L-arginine-HCl throughout pregnancy (14.5 vs. 11.3) or during the first 7 days of pregnancy (14.7 vs. 11.3; Zeng et al., 2008). Concentrations of nitric-oxide metabolites, Arg, proline, glutamine, and ornithine were higher, but urea levels were lower, in serum of arginine-supplemented rats, compared with control rats. These results indicate that dietary Arg supplementation enhances embryonic survival and increases litter size. The underlying mechanisms involve activation of the PI3K/PKB/MTOR signaling pathway (Zeng et al., 2013).

Based on results of animal studies, clinical trials were conducted to evaluate the effects of Arg supplementation to improve fetal-placental growth and prevent IUGR in pregnant women. For example, during late (week 33) gestation, daily intravenous infusion of 
arginine ( $20 \mathrm{~g} /$ day) for 7 days to women with unknown causes of IUGR increased birth weight at term (week 39 ) by $6.4 \%$ (Xiao and $\mathrm{Li}, 2005$ ). Moreover, results of a more recent study indicated that administration of Arg to women with an IUGR fetus was effective in reducing placental apoptosis and improving fetal growth and development (Shen and Hua, 2011). Specifically, after diagnosis of IUGR, pregnant women received a conventional treatment or the conventional treatment plus intravenous Arg (15g in $500 \mathrm{ml} \mathrm{5 \%}$ glucose once daily). Unfortunately, the duration of Arg supplementation was not provided by the authors for the 30 subjects in each group. The prescribed conventional treatment included: left-lateral position, oxygen inhalation for $30 \mathrm{~min}$ two times daily, intravenous administration of magnesium sulfate, oral salbutamol sulphate $(2.4 \mathrm{mg}$ every $8 \mathrm{~h})$, oral multi-vitamin B ( 3 x 1 tablets; i.e., three tablets/day), intravenous fat emulsion $(250 \mathrm{ml} /$ day $)$, and intravenous infusion of $5 \%$ glucose $(500 \mathrm{ml})$. Compared with the control group, arginine administration reduced the level of Bax (an apoptotic protein) in the placenta, increased average birth weight by approximately $53 \mathrm{~g}$, and decreased the incidence of small-for gestational-age newborns (25 vs. 50\%). Finally, a recent meta-analysis of data collected from seven registered clinical trials involving 916 patients revealed that Arg supplementation reduces diastolic blood pressure and prolongs pregnancy in patients with gestational hypertension with or without proteinuria (Gui et al., 2014). Thus, Arg holds great promise to ameliorate preeclampsia in human pregnancy.

\section{Glucose and fructose}

Glucose, a major nutrient for conceptuses and cells of the uterus, is delivered into the uterine lumen by glucose transporters as neither conceptuses nor uterine endometrium carry out gluconeogenesis (see Bazer et al., 2009a; Gao et al., 2009a, b). Transport of glucose from the maternal circulation into the uterine lumen is essential for pregnancy enhancing trophoblast cell growth and proliferation by activating the glutamine:fructose-6-phosphate amidotransferase (GFPT1)-mediated FK506 binding protein 12rapamycin associated protein 1 (FRAP1, formerly mTOR) signaling pathway. Accordingly, total glucose in uterine lumenal fluid increased 6-fold between days 10 and 15 of gestation in ewes in association with rapid blastocyst growth and development from spherical, to tubular and filamentous conceptuses.

Transport of glucose across the plasma membrane can be mediated by one or more members of two distinct families of glucose transporters: facilitative transporters (solute carriers SLC2A; common name is GLUT) and sodium-dependent transporters (sodium/glucose cotransporters SLC5A, common name SGLT). Facilitative glucose transporters are present in developing conceptuses and 13 family members [SLC2A1-SLC2A12 and the $\mathrm{H}^{+}$-coupled myo-inositoltransporter (HMIT)] have, based on order of discovery, been reported. Most of these are expressed in preimplantation blastocysts, although it is uncertain whether SLC2A2 and SLC2A4 are expressed in preimplantation blastocysts. The solute carrier family 2 (facilitated glucose transporter) member 1 (SLC2A1) may be important for transporting glucose into the mouse uterus and conceptuses. Because of its ubiquitous nature in humans and high abundance in periimplantation bovine conceptuses, SLC2A3 plays a critical role in embryonic development, which cannot be compensated for by overexpression of SLC2A1. SLC2A4 has been identified in trophectoderm and endoderm of bovine, rabbit, rat and murine blastocysts and its expression can be regulated by insulin and glucose in the maternal circulation, presumably to regulate uptake of glucose by conceptuses. Despite intensive studies on facilitative glucose transporters, little is known about sodium-dependent glucose transporters (SGLTs) in pre-implantation conceptuses.

During pregnancy, placentae of ungulates (i.e., pigs, horses and ruminants) and cetaceans (e.g., whales and porpoises) are fructogenic, as glucose that is not metabolized immediately is converted into fructose by trophectoderm cells and stored in allantoic fluid (Goodwin, 1956; White et al., 1979; Bazer et al., 2012c). NADPH, the essential cofactor for aldose reductase, is required for the conversion of glucose into sorbitol and, therefore, for fructose production by the placenta. This is consistent with the very high activity of the pentose cycle (the major source of NADPH) in placental cells (Lin et al., 2013). Fructose is the most abundant hexose sugar in fetal fluids of ungulates (Bacon and Bell, 1946, 1948; Barklay et al., 1949; Hitchcock, 1949). In ewes, for example, concentrations of fructose are between 11.1 to $33.3 \mathrm{mM}$ in allantoic fluid during pregnancy whereas the maximum concentration of glucose is only $1.1 \mathrm{mM}$ (Bazer et al., 2012c). Fructose is also present, but as a relatively minor sugar compared with glucose in fetal blood and fetal fluids of humans and other mammals (e.g., dog, cat, guinea pig, rabbit, rat and ferret; Karvonen 1949; Goodwin, 1956; Jauniaux et al., 2005). In general, high levels of fructose are found in the fetal fluids and blood of mammals having epitheliochorial and synepitheliochorial placentae (Goodwin, 1956). However, the roles of fructose during pregnancy in ungulates and cetaceans have not been elucidated because fructose is not metabolized via the glycolytic pathway or the Krebs cycle as an energy source (Fig. 4).

Results of previous studies with pregnant ewes demonstrated that: 1) injection of glucose into ewes caused a rapid elevation in glucose followed by a protracted increase in fructose in fetal blood; 2) the placenta is the site of conversion of glucose to fructose; 3) production of fructose by the placenta is independent of glucose concentration in maternal or fetal blood; and 4) glucose can move from the fetal-placental to the maternal circulation, whereas fructose derived from glucose in the conceptus is not transported into maternal blood (Barklay et al., 1949; Huggett et al., 1951; Alexander et al., 1955a, b). Thus, fructose is a sequestered hexose sugar in ungulates. We used $\mathrm{pTr}$ cells to demonstrate that fructose induces cell proliferation and mRNA translation via stimulation of 
MTORC1 cell signaling which is mediated via the hexosamine biosynthesis pathway (Kim et al., 2012). Western blot analyses of $\mathrm{pTr}$ cell extracts revealed that fructose increased phosphorylated-RPS6K, -EIF4EBP1 and -RPS6 over basal levels within $30 \mathrm{~min}$ and abundance remained elevated to $120 \mathrm{~min}$. Phosphorylation of both RPS6K and EIF4EBP1 proteins in response to fructose was inhibited by inhibitors of both PI3K and MTOR. Further, inhibition of GFPT1 by azaserine (inhibitor of GFPT1) and GFPT1 siRNA led us to discover that MTOR-RPS6K and MTOREIF4EBP1 signaling in response to fructose is mediated via GFPT1 activation and the hexosamine pathway. We further demonstrated that fructose stimulates production of hyaluronic acid via GFPT1 and the hexosamine biosynthesis pathway. These novel results demonstrated critical roles for fructose that are mediated via the hexosamine biosynthesis pathway to stimulate MTOR cell signaling, proliferation of $\mathrm{pTr}$ cells and synthesis of hyaluronic acid, a significant glycosaminoglycan in the placenta, during pregnancy (Kim et al., 2012). We also have strong evidence that fructose affects the proliferative behavior of conceptus trophectoderm/chorion via activation of the Akt-TSC2MTOR signaling cascade, as phosphorylation for activation of this cascade is mediated by $O$ GlcNAcylation from UDP-N-acetylglucosamine (UDPGlcNAc), a primary product of fructose metabolism via the hexosamine biosynthesis pathway (Wang et al. 2016). Collectively, these results reveal novel functional roles of fructose in promoting embryonic/fetal growth and development during pregnancy, and also provide new insight into understanding the relationship between excessive fructose intake and metabolic disorders. We hypothesize that fructose is produced and metabolized by the placenta via the pathways for hexosaamine biosynthesis and serinogenesis whereas glucose is utilized by the embryo for metabolism via pathways for glycolysis, serinogenesis, pentose phosphate pathway and hexosamine biosynthesis (Fig. 5).
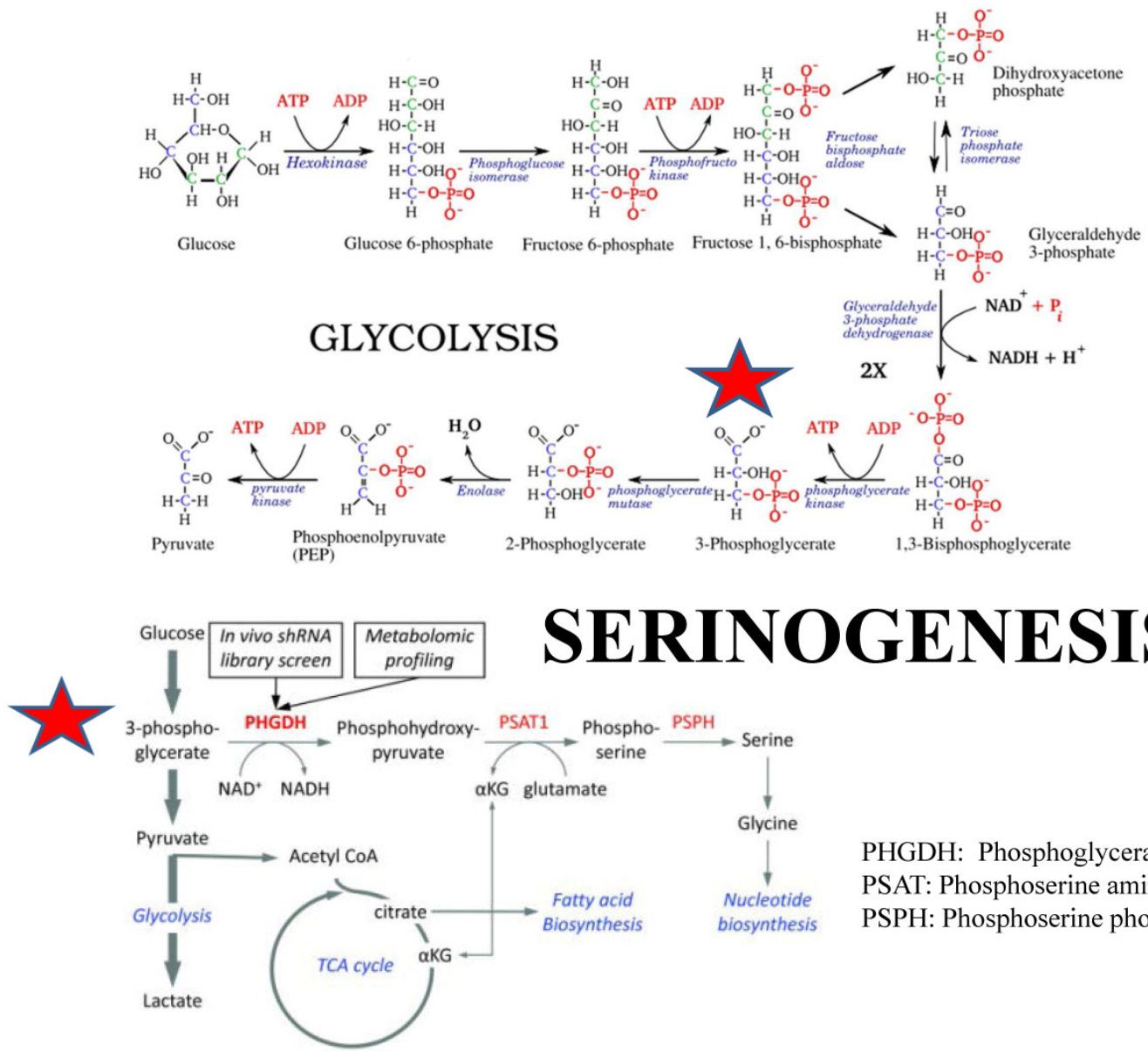

PHGDH: Phosphoglycerate dehydrogenase PSAT: Phosphoserine aminotransferase PSPH: Phosphoserine phosphatase

Figure 4. Fructose is the most abundant hexose sugar in fetal blood and fetal fluids of ungulates and cetaceans. Glucose and fructose may be metabolized via a modification of the glycolytic pathway to 3-phosphoglycerate which can then be metabolized to phosphohydroxy pyruvate, then phosphoserine and then serine. Serine is converted to glycine which is used for synthesis of purines, thymidine and s-adenosyl methionine. Phosphoglycerate dehydrogenase, PHGDH; Phosphoserine aminotransferase, PSAT1; phosphoserine phosphatase, PSPH. (See Kim et al., 2012; Amelio et al., 2014; Ben-Sahara et al., 2016). 


\section{Fructose Metabolism Supports Placental Development While Glucose Metabolism Supports Embryonic/Fetal Development}

\author{
Glucose: Embryo/Fetus
}

Fructose: Trophectoderm/Chorioallantois

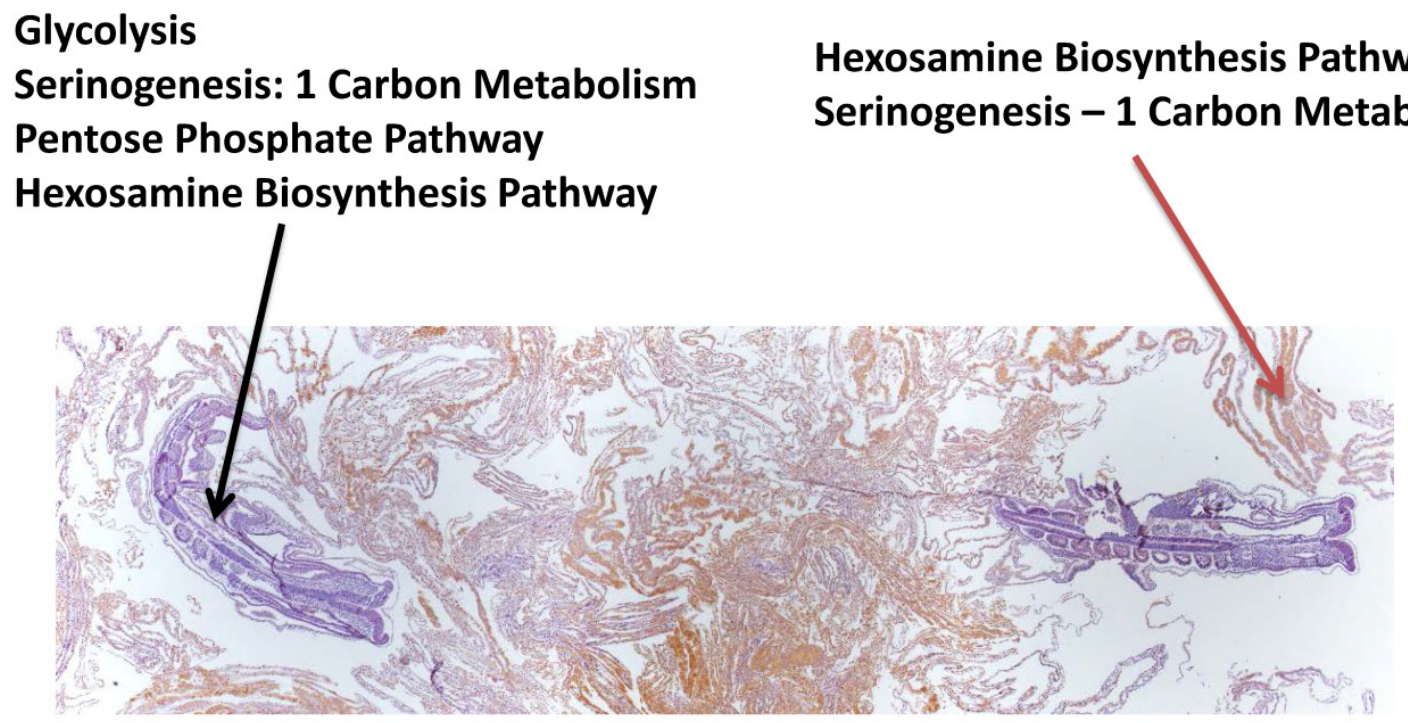

Figure 5. In ungulates and cetaceans, glucose not utilized by the embryo/fetus is converted to fructose; however, the role(s) of fructose have not been established. It is known that fructose is not metabolized via the glycolytic pathway or the pentose phosphate pathway; however, it may be metabolized via the pathways for serinogenesis and hexosamine biosynthesis. We propose that glucose is metabolized via the embryo/fetus for each of the four metabolic pathways, while fructose is utilized by the placenta for serinogenesis and hexosamine biosynthesis (See Kim et al., 2012; Amelio et al., 2014; Ben-Sahara et al., 2016)

As noted previously, fructose is metabolized to fructose-6-phosphate in both ovine and porcine placental cells. We suggest that fructose-6-P is preferentially channeled to GFPT1 for reaction with glutamine, producing glucosamine-6-P, rather than being irreversibly degraded to lactate via glycolysis. Of interest, in the formation of glucosamine-6-P from fructose, all the fructose carbons are conserved. Fructose conservation may be important for the fetus. Another possibility for the lack of lactate production from fructose is intracellular compartmentalization for D-fructose metabolism. In amino acid metabolism, the concept of intracellular compartmentalization is now well accepted (Wu, 2013). However, we are not aware of any data on the possible presence of intracellular compartmentalization of glucose or fructose metabolism in animal cells, except for the trafficking of glycosylated proteins among cellular organelles.

\section{Summary and Conclusions}

This review has drawn attention to the fact that there are various mechanisms for pregnancy recognition signaling and the manner in which the anitluteolytic or luteotrophic signal acts to protect the CL for production of progesterone, the hormone of pregnancy. In addition, there is interplay between progesterone and pregnancy recognition signaling molecules that induce changes in gene expression within the uterus in a cell-specific and temporal manner. Those genes affect many aspects of uterine biology including induction of nutrient transporters for delivery of nutrients to the conceptus, as well as modify the uterus to allow for implantation and placentation essential for a successful outcome of pregnancy.

\section{Acknowledgments}

Research presented in this paper was supported by USDA CSREES National Research Initiative Grant 2006-35203-17283 and Agriculture and Food Research Initiative Competitive Grants no. 2011-67015-20028 and 2016-67015-24958 from the USDA National Institute of Food and Agriculture, National Research Initiative Competitive Grant No. 2006-35203-17283 from the USDA National Institute of Food and Agriculture, and the World Class University (WCU) program (R31-10056) through the National Research Foundation of Korea funded by the Ministry of Education, Science, and Technology.

\section{Conflict of interest}

The authors declare no conflicts of interest. 


\section{References}

Aboagye-Mathiesen G, Toth FD, Zdravkovic M, Ebbesen P. 1995. Human trophoblast interferons: production and possible roles in early pregnancy. Early Pregnancy, 1:41-53.

Alexander DP, Andrews RD, Huggett AS, Nixon DA, Widdas WF. 1995a. The placental transfer of sugars in the sheep: studies with radioactive sugar. J Physiol, 129:352-366

Alexander DP, Huggett AS, Nixon DA, Widdas WF. 1955b. The placental transfer of sugars in the sheep: the influence of concentration gradient upon the rates of hexose formation as shown in umbilical perfusion of the placenta. J Physiol, 129:367-383.

Amelio I, Cutruzzola F, Antonov A, Agostini M, Melino G. 2014. Serine and glycine metabolism in cancer. Trends Biochem Sci, 39:191-198.

Anderson LL. 1993. Pigs. In: Hafez ESE (Ed). Reproduction in Farm Animals. Philadelphia, PA: Lea \& Febiger. pp. 343-360.

Austin KJ, Bany BM, Belden EL, Rempel LA, Cross JC, Hansen TR. 2003. Interferon-stimulated gene-15 (Isg15) expression is up-regulated in the mouse uterus in response to the implanting conceptus. Endocrinology, 144:3107-3113.

Bacon JS, Bell DJ. 1946. The identification of fructose as a constituent of the foetal blood of the sheep. Biochem J, 40:xlii, 1946.

Bacon JS, Bell DJ. 1948. Fructose and glucose in the blood of the foetal sheep. Biochem J, 42:397-405.

Bany BM, Cross JC. 2006. Post-implantation mouse conceptuses produce paracrine signals that regulate the uterine endometrium undergoing decidualization. Dev Biol, 294:445-456.

Barklay H, Haas P, Huggett ASG, King G, Rowley D. 1949. The sugar of the foetal blood, the amniotic and allantoic fluids. J Physiol, 109:98-102.

Bartol FF, Wiley AA, Bagness CA. 2006. Uterine development and endometrial programming. Soc Reprod Fertil Suppl, 62:113-130.

Bazer FW, Thatcher WW. 1977. Theory of maternal recognition of pregnancy in swine based on estrogen controlled endocrine versus exocrine secretion of prostaglandin F2a by the uterine endometrium. Prostaglandins, 14:397-401.

Bazer FW, Goldstein MH, Barron DH. 1981. Water and electrolyte transport by pig chorioallantois. In: Mastroianni L, Biggers JD, Sadler WA (Ed.). Fertilization and Embryonic Development In Vitro. New York, NY: Plenum Publishing. pp. 289-321.

Bazer FW, Burghardt RC, Johnson GA, Spencer TE, Wu G. 2008. Interferons and progesterone for establishment and maintenance of pregnancy: Interactions among novel cell signaling pathways. Reprod Biol, 8:179-211.

Bazer FW, Gao H, Johnson GA, Wu G, Bailey DW, Burghardt RC. 2009a. Select nutrients and glucose transporters in pig uteri and conceptuses. Soc Reprod Fertil Suppl, 66:335-336.

Bazer FW, Spencer TE, Johnson GA. 2009b. Interferons and uterine receptivity. Semin Reprod Med,

\section{7:90-102}

Bazer FW, Spencer TE, Johnson GA, Burghardt RC, Wu G. 2009c. Comparative aspects of implantation. Reproduction, 138:195-209.

Bazer FW, Kim J, Song G, Satterfield MC, Johnson GA, Burgardt RC, Wu G. 2012a. Uterine environment and conceptus development in ruminants. Anim Reprod, 9:297-304

Bazer FW, Satterfield MC, Song G. 2012b. Modulation of uterine function by endocrine and paracrine factors in ruminants. Anim Reprod, 9:305-311. Bazer FW, Spencer TE, Thatcher WW. 2012c. Growth and development of the ovine conceptus. $J$ Anim Sci, 90:159-170.

Bazer FW, Johnson GA. 2014. Pig blastocyst-uterine interactions. Differentiation, 87:52-65.

Bazer FW, Johnson GA, Wu G. 2015. Amino acids and conceptus development during the peri-implantation period of pregnancy. Adv Exp Med Biol, 843:23-52.

Ben-Jonathan N, LaPensee CR, LaPensee EW. 2008. What can we learn from rodents about prolactin in humans? Endocr Rev, 29:1-41.

Ben-Sahra I, Hoxhaj G, Ricoult SJH, Asara JM, Manning BD. 2016. mTORC1 induces purine synthesis through control of the mitochondrial tetrahydrofolate cycle. Science, 351:728-732.

Bérard J, Bee G. 2010. Effects of dietary 1-arginine supplementation to gilts during early gestation on foetal survival, growth and myofiber formation. Animal, 4:1680-1687.

Burton GJ, Jauniaux E, Charnock-Jones DS. 2007. Human early placental development: potential roles of the endometrial glands. Placenta, 28(suppl. A):S64-69.

Campbell R. 2009. Pork CRC - NZ Seminar Series: arginine and reproduction. Available on: http://www/nzpib.co.nz.

Dantzer V. 1984. Scanning electron microscopy of exposed surfaces of the porcine placenta. Acta Anat, 118:96-106.

De Blasio M, Roberts C, Owens J. 2009. Effect of dietary arginine supplementation during gestation on litter size of gilts and sows. Available on: http://www.australianpork.com.au.

Duggavathi R, Volle DH, Mataki C, Antal MC, Messaddeq N, Auwerx J, Murphy BD, Schoonjans K. 2008. Liver receptor homolog 1 is essential for ovulation. Genes Dev, 22:1871-1876.

Duggavathi R, Murphy BD. 2009. Ovulation signals. Science, 324:890-891.

Fazleabas AT, Kim JJ, Strakova Z. 2004. Implantation: embryonic signals and the modulation of the uterine environment: a review. Placenta, 25:S26S31.

Freeman ME, Smith MS, Nazian SJ, Neill JD. 1974. Ovarian and hypothalamic control of the daily surges of prolactin secretion during pseudopregnancy. Endocrinology, 94:875-882.

Gao H, Wu G, Spencer TE, Johnson GA, Bazer FW. 2009a. Select nutrients in the ovine uterine lumen. II. glucose transporters in the uterus and peri-implantation conceptuses. Biol Reprod, 80:94-104.

Gao H, Wu G, Spencer TE, Johnson GA, Li X, Bazer 
FW. 2009b. Select nutrients in the ovine uterine lumen: I. Amino acids, glucose and ions in uterine lumenal fluid of cyclic and pregnant ewes. Biol Reprod, 80:8693.

Gao KG, Jiang ZY, Lin YC, Zheng C, Zhou G, Chen F, Yang L, Wu G. 2012. Dietary L-arginine supplementation enhances placental growth and reproductive performance in sows. Amino Acids, 42:2207-2214.

Gardner DK, Lane M, Batt P. 1993. Uptake and metabolism of pyruvate and glucose by individual sheep preattachment embryos developed in vivo. Mol Reprod Dev, 36:313-319.

Geisert RD, Yelich JV. 1997. Regulation of conceptus development and attachment in pigs. $J$ Reprod Fertil Suppl, 52:133-49.

Gellersen B, Fernandes MS, Brosens JJ. 2008. Nongenomic progesterone actions in female reproduction. Hum Reprod Update, 15:119-138.

Goldstein MH, Bazer FW, Spellacy WN, Buhi WC. 1976. Stimulation of active transport across porcine and human placentae by human placental lactogen. Gynecol Invest, 7:58.

Goodwin RF. 1956. Division of the common mammals into two groups according to the concentration of fructose in the blood of the foetus. J Physiol, 132:146156.

Gray CA, Taylor KM, Ramsey WS, Hill JR, Bazer FW, Bartol FF, Spencer TE. 2001. Endometrial glands are required for preimplantation conceptus elongation and survival. Biol Reprod, 64:1608-1613.

Gresores A, Anderson S, Hood D, Zerbe GO, Hay WW Jr. 1997. Separate and joint effects of arginine and glucose on ovine fetal insulin secretion. Am J Physiol, 72:E68-73.

Grillo MA, Lanza A, Colombatto S. 2008. Transport of amino acids through the placenta and their role. Amino Acids, 34:517-523.

Gu Y, Srivastava RK, Ou J, Krett NL, Mayo KE, Gibori G. 1995. Cell-specific expression of activin and its two binding proteins in the rat decidua: role of $\alpha 2$ macroglobulin and follistatin. Endocrinology, 136: 3815-3822.

Gui S, Jia J, Niu X, Bai Y, Zou H, Deng J, Zhou R. 2014. Arginine supplementation for improving maternal and neonatal outcomes in hypertensive disorder of pregnancy: a systematic review. J Renin Angiotensin Aldosterone System, 15:88-96.

Guillomot M, Flechon JE, Leroy F. 1993. Blastocyst development and implantation. In: Thibault $\mathrm{C}$, Levasseur MC, Hunter RHF (Ed.). Reproduction in Mammals and Man. Paris: Ellipses. pp. 387-411.

Hess AP, Hamilton AE, Talbi S, Dosiou, C, Nyegaard, $M$, Nayak $N$, Genbecev-Krtolica $O$, Mavrogianis P, Ferrer K, Kruessel J, Fazleabas AT, Fisher SJ, Giudice LC. 2007. Decidual stromal cell response to paracrine signals from the trophoblast: amplification of immune and angiogenic modulators. Biol Reprod, 76:102-117.

Hitchcock MW. 1949. Fructose in the sheep foetus. $J$ Physiol, 108:117-126.

Huggett AS, Warren FL, Warren NV. 1951. The origin of the blood fructose of the foetal sheep. $J$ Physiol, 113:258-275.

Irvine CHG. 1995. The nonpregnant mare: a review of some current research and of the last 25 years of endocrinology. In: Bazer FW, Sharp DC (Ed.). Equine Reproduction IV. London: Portland Press. pp. 343-360. (Biol Reprod Mono Series, 1).

Jauniaux E, Hempstock J, Teng C, Battaglia FC, Burton GJ. 2005. Polyol concentrations in the fluid compartments of the human conceptus during the first trimester of pregnancy: maintenance of redox potential in a low oxygen environment. J Clin Endocrinol Metab, 90:1171-1175.

Jobgen WS, Fried SK, Fu FW, Meininger CJ, Wu G. 2006. Regulatory role for the arginine-nitric oxide pathway in metabolism of energy substrates. $J$ Nutr Biochem, 17:571-588.

Johnson GA, Bazer FW, Burghardt RC, Spencer TE, Wu G, Bayless KJ. 2009. Conceptus-uterus interactions in pigs: endometrial gene expression in response to estrogens and interferons from conceptus. Soc Reprod Fertil Suppl, 66:321-332.

Ka H, Al-Ramadan S, Erikson DW, Johnson GA, Burghardt RC, Spencer TE, Jaeger LA, Bazer FW. 2007. Regulation of fibroblast growth factor 7 expression in the pig uterine endometrium by progesterone and estradiol. Biol Reprod, 77:172-180.

Karvonen MJ. 1949. Absence of fructose from human cord blood. Acta Paediatr, 37:68-72.

Kensinger RS, Collier RJ, Bazer FW, Ducsay CA, Becker HN. 1980. Nucleic acid, metabolic and histological changes in gilt mammary tissue during pregnancy and lactogenesis. Biol Reprod, 22:11681180.

Kim J, Erikson DW, Burghardt RC, Spencer TE, Wu G, Bayless KJ, Johnson GA, Bazer FW. 2010. Secreted phosphoprotein 1 binds integrins to initiate multiple cell signaling pathways, including FRAP1/mTOR, to support attachment and forcegenerated migration of trophectoderm cells. Matrix Biol, 29:369-382.

Kim J, Burghardt RC, Wu G, Johnson GA, Spencer TE, Bazer FW. 2011. Select Nutrients in the ovine uterine lumen: VIII. Arginine stimulates proliferation of ovine trophectoderm cells through mTOR RPS6K RPS6 signaling cascade and synthesis of nitric oxide and polyamines. Biol Reprod, 84:62-69.

Kim J, Song G, Wu G, Bazer FW. 2012. Functional roles of fructose. Proc Natl Acad Sci USA, 109:E1619. 1628.

Kim JY, Song GH, Wu G, Gao HJ, Johnson GA, Bazer FW. 2013. Arginine, leucine, and glutamine stimulate proliferation of porcine trophectoderm cells through the MTOR-RPS6K-RPS6-EIF4EBP1 signal transduction pathway. Biol Reprod, 88:113-120.

Knight JW, Bazer FW, Thatcher WW, Franke DE, Wallace HD. 1977. Conceptus development in intact and unilaterally hysterectomized-ovariectomized gilts: Interrelations among hormonal status, placental development, fetal fluids and fetal growth. J Anim Sci, 44:620-637.

Kong X, Tan B, Yin Y, Gao H, Li X, Jaeger LA, 
Bazer FW, Wu G. 2012. L-Arginine stimulates the mTOR signaling pathway and protein synthesis in porcine trophectoderm cells. J Nutr Biochem, 23:11781183.

Kwon H, Spencer TE, Bazer FW, Wu G. 2003 Developmental changes of amino acids in ovine fetal fluids. Biol Reprod, 68:1813-1820.

Kwon H, Ford SP, Bazer FW, Spencer TE, Nathanielsz PW, Nijland MW, Hess BW, Wu G. 2004a. Maternal nutrient restriction reduces concentrations of amino acids and polyamines in ovine maternal and fetal plasma and fetal fluids. Biol Reprod, 71:901-908.

Kwon H, Wu G, Meininger CJ, Bazer FW, Spencer TE. 2004b. Developmental changes in nitric oxide synthesis in the ovine placenta. Biol Reprod, 70:679686.

Lassala A, Bazer FW, Cudd TA, Datta S, Keisler DH, Satterfield MC, Spencer TE, Wu G. 2010 Parenteral administration of L-arginine prevents fetal growth restriction in undernourished ewes. $J$ Nutr, 140:1242-1248

Lassala A, Bazer FW, Cudd TA, Datta S, Keisler DH, Satterfield MC, Spencer TE, Wu G. 2011 . Parenteral administration of 1-arginine enhances fetal survival and growth in sheep carrying multiple fetuses. J Nutr, 141:849-855.

Li XL, Bazer FW, Johnson GA, Burghardt RC, Erikson DW, Frank JW, Spencer TE, Shinzato I, Wu G. 2010. Dietary supplementation with $0.8 \%$ Larginine between days 0 and 25 of gestation reduces litter size in gilts. $J$ Nutr, 140:1111-1116.

Li XL, Bazer FW, Johnson GA, Burghardt RC, Frank JW, Dai ZL, Wang JJ, Wu ZL, Shinzato I, Wu G. 2014. Dietary supplementation with L-arginine between days 14 and 25 of gestation enhances embryonic development and survival in gilts. Amino Acids, 46:375-384

Lin G, Li DF, Wang JJ, Bazer FW, Wu G. 2013 Stimulation of pentose cycle activity in porcine trophectoderm cells by L-glutamine, but not L-arginine. Amino Acids, 45:603-604.

Luther JS, Windorski EJ, Schauer CS. 2008. Impacts of L-arginine on ovarian function and reproductive performance in ewes. J Anim Sci, 286(E-suppl.):ii.

Martin PM, Sutherland AE. 2001. Exogenous amino acids regulate trophectoderm differentiation in the mouse blastocyst through an mTOR-dependent pathway. Dev Biol, 240:182-193.

Martin PM, Sutherland AE, Winkle LJV. 2003. Amino acid transport regulates blastocyst implantation. Biol Reprod, 69:1101-1108.

Mateo RD, Wu G, Bazer FW, Park JC, Shinzato I, Kim SW. 2007. Dietary L-arginine supplementation enhances the reproductive performance of gilts. $J$ Nutr, 137:652-656.

McCoard SA, Sales FA, Sciascia QL. 2016. Amino acids in sheep production. Front Biosci, E8:264-288.

Morris DG, Diskin MG, Sreenan JM. 2000. Protein synthesis and phosphorylation by elongating 13-15-dayold cattle blastocysts. Reprod Fertil Dev, 12:39-44.

Morris DG, Humpherson PG, Leese HJ, Sreenan
JM. 2002. Amino acid turnover by elongating cattle blastocysts recovered on days 14-16 after insemination. Reproduction, 124:667-573.

Newton GR, Ott TL, Woldesenbet S, Shelton AH, Bazer FW. 1996. Biochemical and immunological properties of related small ruminant trophoblast interferons. Theriogenology, 46:703-716.

Nilsson EE, Stanfield J, Skinner MK. 2006. Interactions between progesterone and tumor necrosis factor-a in the regulation of primordial follicle assembly. Reproduction, 132:877-886.

Noel S, Herman A, Johnson GA, Gray CA, Stewart MD, Bazer FW, Gertler A, Spencer TE. 2003. Ovine placental lactogen specifically binds to endometrial glands of the ovine uterus. Biol Reprod, 68:772-780.

Perry JS, Crombie PR. 1982. Ultrastructure of the uterine glands of the pig. J Anat, 134:339-350.

Platanias LC. 2005. Mechanisms of type-I- and typeII-interferon-mediated signalling. Nat Rev Immunol, 5:375-386.

Pond WG, Strachan DN, Sinha YN, Walker EF Jr, Dunn JA, Barnes RH. 1969. Effect of protein deprivation of swine during all or part of gestation on birth weight, postnatal growth rate and nucleic acid content of brain and muscle of progeny. $J$ Nutr, 99:6167.

Pond WG, Wu JF. 1981. Mature body weight and life span of male and female progeny of primiparous rats fed a low protein or adequate diet throughout pregnancy. J Nutr, 111:1949-1954.

Ramaekers P, Kemp B, van der Lende T. 2006. Progenos in sows increases number of piglets born. $J$ Anim Sci, 84(suppl. 1):394. (abstract).

Rao CV. 2001. Multiple novel roles of luteinizing hormone. Fertil Steril, 76:1097-1100.

Regnault TR, de Vrijer B, Battaglia FC. 2002. Transport and metabolism of amino acids in placenta. Endocrine, 19:23-41.

Rieger D, Loskutoff NM, Betteridge KJ. 1992. Developmentally related changes in the uptake and metabolism of glucose, glutamine and pyruvate by cattle embryos produced in-vitro. Reprod Fertil Dev, 4:547557.

Roberto da Costa RP, Costa AS, Korzekwa AJ, Platek R, Siemieniuch M, Galvão A, Redmer DA, Silva JR, Skarzynski DJ, Ferreira-Dias G. 2008. Actions of a nitric oxide donor on prostaglandin production and angiogenic activity in the equine endometrium. Reprod Fertil Dev, 20:674-83.

Salvemini D, Misko TP, Masferrer JL, Seibert K, Currie MG, Needleman P. 1993. Nitric oxide activates cyclooxygenase enzymes. Proc Natl Acad Sci USA, 90:7240-7244

Satterfield MC, Bazer FW, Spencer TE, Wu G. 2010. Sildenafil citrate treatment enhances amino acid availability in the conceptus and fetal growth in an ovine model of intrauterine growth restriction. $J$ Nutr, 140:251-258.

Satterfield MC, Dunlap KA, Keisler DH, Bazer FW, Wu G. 2012. Arginine nutrition and fetal brown adipose tissue development in diet-induced obese sheep. Amino Acids, 43:1593-1603. 
Seo JW, Sung Y, Ka H, Song G, Kim J. 2016. Lysophosphatidic acid (LPA) receptor 3-mediated lpa signal transduction pathways: a possible relationship with early development of peri-implantation porcine conceptus. Biol Reprod, 94:104. doi: 10.1095/biolreprod.115.137174.

Sharp DC, McDowell KJ, Weithenauer J, Thatcher WW. 1989. The continuum of events leading to maternal recognition of pregnancy in mares. $J$ Reprod Fertil Suppl, 37:101-107.

Shen SF, Hua CH. 2011. Effect of L-arginine on the expression of Bcl-2 and Bax in the placenta of fetal growth restriction. $J$ Matern Fetal Neonatal Med, 24:822-826.

Sherwood DO. 2004. Relaxin's physiological roles and other diverse actions. Endocr Rev, 25:205-234.

Slayden OD, Keater CS. 2007. Role of progesterone in nonhuman primate implantation. Semin Reprod Med, 25:418-430.

Soares MJ, Konno T, Khorshed Alam SKM. 2007. The prolactin family: effectors of pregnancy-dependent adaptations. Trends Endocrinol Metab, 18:114-121.

Spencer TE, Ott TL, Gertler A, Gootwine E, Bazer FW. 1999. Effects of recombinant ovine interferon tau, placental lactogen and growth hormone on the ovine uterus. Biol Reprod, 61:1409-1418.

Spencer TE, Bazer FW. 2004. Uterine and placental factors regulating conceptus growth in domestic animals. J Anim Sci, 82(E-suppl):E4-13.

Spencer TE, Burghardt RC, Johnson GA, Bazer FW. 2004. Conceptus signals for establishment and maintenance of pregnancy. Anim Reprod Sci, 82/83:537-550.

Spencer TE, Johnson GA, Bazer FW, Burghardt RC, Palmarini M. 2007. Pregnancy recognition and conceptus implantation in domestic ruminants: roles of progesterone, interferons and endogenous retroviruses. Reprod Fertil Dev, 19:65-78.

Stewart DM, Johnson GA, Gray CA, Schuler LA, Burghardt RC, Joyce MM, Bazer FW, Spencer TE. 2000. Prolactin receptor and uterine milk protein expression in the ovine uterus during the estrous cycle and early pregnancy. Biol Reprod, 62:1779-1789.

Stewart DM, Johnson GA, Vyhlidal CA, Burghardt RC, Safe SH, Yu-Lee LY, Bazer FW, Spencer TE. 2001. Interferon tau activates multiple STAT proteins and has complex effects on interferon-responsive gene transcription in ovine endometrial epithelial cells. Endocrinology, 142:1786-1794.

Stouffer RL. 1988. Perspectives on the corpus luteum of the menstrual cycle and early pregnancy. Semin Reprod Endocrinol, 6:103-113.

Tayade C, Cnossen S, Wessels J, Linton N, Quinn B, Waelchi R, Croy AB, Hayes M, Betteridge K. 2008 . IFN- $\delta$, a Type I interferon is expressed by both the conceptus and endometrium during early equid pregnancy. In: Proceedings of the 41 st Annual Meeting of the Society for the Study of Reproduction, Kona, Hawaii. Madison, WI: SSR. Abstr 83.

Thatcher WW, Guzeloglu A, Mattos R, Binelli M, Hansen TR, Pru JK. 2001. Uterine-conceptus interactions and reproductive failure in cattle.
Theriogenology, 56:1435-1450.

Thomas P. 2008. Characteristics of membrane progestin receptor alpha $(\mathrm{mPRa})$ and progesterone membrane receptor component 1 (PGMRC1) and their roles in mediating rapid progestin actions. Front Neuroendocrinol, 29:292-312.

Thureen PJ, Baron KA, Fennessey PV, Hay WW Jr. 2002. Ovine placental and fetal arginine metabolism at normal and increased maternal plasma arginine concentrations. Pediatr Res, 51:464-471.

Wales RG, Du ZF. 1994. The metabolism of glutamine by the preimplantation sheep conceptus and its interaction with glucose. Reprod Fertil Dev, 6:659-667. Wang X, Li D, Wu G, Bazer FW. 2016. Functional roles of fructose: Crosstalk between O-linked glycosylation and phosphorylation of Akt-TSC2-MTOR cell signaling cascade. Biol Reprod, (in press)

White FJ, Ross JW, Joyce MM, Geisert RD, Burghardt RC, Johnson GA. 2005. Steroid regulation of cell specific secreted phosphoprotein 1 (osteopontin) expression in the pregnant porcine uterus. Biol Reprod, 73:1294-1301

Wu G, Bazer FW, Tuo W. 1995. Developmental changes of free amino acid concentrations in fetal fluids of pigs. J Nutr, 125:2859-2868.

Wu G, Bazer FW, Tuo W, Flynn SP. 1996. Unusual abundance of arginine and ornithine in porcine allantoic fluid. Biol Reprod, 54:1261-1265.

Wu G, Bazer FW, Hu J, Johnson GA, Spencer TE. 2005. Polyamine synthesis from proline in the developing porcine placenta. Biol Reprod, 72:842-850.

Wu G, Bazer FW, Wallace JM, Spencer TE. 2006. Intrauterine growth retardation: Implications for the animal sciences. J Anim Sci, 84:2316-2337.

Wu G, Bazer FW, Cudd TA, Jobgen WS, Kim SW, Lassala A, Li P, Matis JH, Meininger CJ, Spencer TE. 2007a. Pharmacokinetics and safety of arginine supplementation in animals. $J$ Nutr, 137:1673S-1680S.

Wu G, Bazer FW, Davis TA, Jaeger LA, Johnson GA, Kim SW, Knabe DA, Meininger CJ, Spencer TE, Yin YL. 2007b. Important roles for the arginine family of amino acids in swine nutrition and production. Livest Sci, 112:8-22.

Wu G, Bazer FW, Datta S, Johnson GA, Li P, Satterfield MC, Spencer TE. 2008. Proline metabolism in the conceptus: Implications for fetal growth and development. Amino Acids, 35:691-702.

Wu G, Bazer FW, Davis TA, Kim SW, Li P, Marc Rhoads J, Carey Satterfield M, Smith SB, Spencer TE, Yin Y. 2009. Arginine metabolism and nutrition in growth, health and disease. Amino Acids, 37:153-168.

Wu G, Meininger CJ. 2009. Nitric oxide and vascular insulin resistance. BioFactors, 35: 21-27.

Wu G. 2010. Functional amino acids in growth, reproduction and health. Adv Nutr, 1:31-37.

Wu G, Bazer FW, Burghardt RC, Johnson GA, Kim SW, Li XL, Satterfield MC, Spencer TE. 2010. Impacts of amino acid nutrition on pregnancy outcome in pigs: mechanisms and implications for swine production. J Anim Sci, 88:E195-E204.

Wu G, Bazer FW, Burghardt RC, Johnson GA, Kim SW, Knabe DA, Li P, Li X, McKnight JR, Satterfield 
MC, Spencer TE. 2011a. Proline and hydroxyproline metabolism: implications for animal and human nutrition. Amino Acids, 40:1053-1063.

Wu G, Bazer FW, Johnson GA, Knabe DA, Burghardt RC, Spencer TE, Li XL, Wang JJ. 2011 b. Important roles for L-glutamine in swine nutrition and production. J Anim Sci, 89:2017-2030.

Wu G, Imhoff-Kunsch B, Girard AW. 2012. Biological mechanisms for nutritional regulation of maternal health and fetal development. Paediatr Perinatal Epidemiol, 26(suppl. 1):4-26.

Wu G. 2013. Amino Acids: Biochemistry and Nutrition. Boca Raton, FL: CRC Press. 503 pp.

Wu G, Bazer FW, Johnson GA, Burghardt RD, Li XL, Dai ZL, Wang JJ, Wu ZL. 2013a. Maternal and fetal amino acid metabolism in gestating sows. Soc Reprod Fertil Suppl, 68:185-198.

Wu G, Bazer FW, Satterfield MC, Li XL, Wang XQ, Johnson GA, Burghardt RC, Dai ZL, Wang JJ, Wu ZL. 2013b. Impacts of arginine nutrition on embryonic and fetal development in mammals. Amino Acids, 45:241-256

Wu G, Wu ZL, Dai ZL, Yang Y, Wang WW, Liu C, Wang B, Wang JJ, Yin Y. 2013c. Dietary requirements of "nutritionally nonessential amino acids" by animals and humans. Amino Acids, 44:1107-1113.
Wynn M, Wynn A. 1988. Nutrition around conception and the prevention of low birthweight. Nutr Health, 6:37-52.

Xiao XM, Li LP. 2005. L-arginine treatment for asymmetric fetal growth restriction. Int $J$ Gynecol Obstet, 88:15-18.

Young KH, Kraeling RR, Bazer FW. 1990. Effect of pregnancy and exogenous ovarian steroids on endometrial prolactin receptor ontogeny and uterine secretory response in pigs. Biol Reprod, 43:592-599.

Zeng X, Wang F, Fan X, Yang W, Zhou B, Li P, Yin Y, Wu G, Wang J. 2008. Dietary arginine supplementation during early pregnancy enhances embryonic survival in rats. $J$ Nutr, 138:1421-1425.

Zeng X, Huang Z, Mao X, Wang J, Wu G, Qiao S. 2012. Arginine enhances embryo implantation in rats through $\mathrm{PI} 3 \mathrm{~K} / \mathrm{Akt} / \mathrm{mTOR} / \mathrm{NO}$ signaling pathway during early pregnancy. PLoS One, 7:e41192.

Zeng X, Mao X, Huang Z, Wang F, Wu G, Qiao S. 2013. Arginine enhances embryo implantation in rats through $\mathrm{PI} 3 \mathrm{~K} / \mathrm{PKB} / \mathrm{mTOR} / \mathrm{NO}$ signaling pathway during early pregnancy. Reproduction, 145:1-7.

Ziecik AJ, Kaczmarek MM, Blitek A, Kowalczyk AE, Li X, Rahmanc NA. 2007. Novel biological and possible applicable roles of LH/hCG receptor. Mol Cell Endocrinol, 269:51-60. 